\title{
An Evaluation of the Effectiveness of a Nurse-Led Telephone Program for Patients with Heart Failure on Quality of Life, Anxiety, Depression, and 30 Day Hospital Readmissions
}

\author{
Brooke Leaberry \\ West Virginia University
}

Follow this and additional works at: https://researchrepository.wvu.edu/etd

\section{Recommended Citation}

Leaberry, Brooke, "An Evaluation of the Effectiveness of a Nurse-Led Telephone Program for Patients with Heart Failure on Quality of Life, Anxiety, Depression, and 30 Day Hospital Readmissions" (2011). Graduate Theses, Dissertations, and Problem Reports. 3074.

https://researchrepository.wvu.edu/etd/3074

This Dissertation is protected by copyright and/or related rights. It has been brought to you by the The Research Repository @ WVU with permission from the rights-holder(s). You are free to use this Dissertation in any way that is permitted by the copyright and related rights legislation that applies to your use. For other uses you must obtain permission from the rights-holder(s) directly, unless additional rights are indicated by a Creative Commons license in the record and/ or on the work itself. This Dissertation has been accepted for inclusion in WVU Graduate Theses, Dissertations, and Problem Reports collection by an authorized administrator of The Research Repository @ WVU.

For more information, please contact researchrepository@mail.wvu.edu. 
An Evaluation of the Effectiveness of a Nurse-Led Telephone Program for Patients with Heart Failure on Quality of Life, Anxiety, Depression, and 30 Day Hospital Readmissions

Brooke Leaberry

Doctoral Research Project submitted to the

School of Nursing

at West Virginia University

in partial fulfillment of the requirements

for the degree of

Doctor of Nursing Practice

\author{
Susan McCrone, PhD, Chair \\ Jennifer Riggs, PhD \\ Margaret Bowers, MSN, FNP-BC \\ Mark Studeny, MD \\ Department of Health Sciences
}

Morgantown, West Virginia

2011

Keywords: heart failure, phone, nurse led, intervention, depression, anxiety 


\begin{abstract}
An Evaluation of the Effectiveness of a Nurse-Led Telephone Program for Patients with Heart Failure on Quality of Life, Anxiety, Depression, and 30 Day Hospital Readmissions
\end{abstract}

\title{
Brooke Leaberry
}

Introduction: The prevalence of heart failure $(\mathrm{HF})$ has continued to increase around the globe in the past 30 years. Despite advanced technology and rigorous management protocols, patients diagnosed with HF continue to suffer heart failure symptoms. These debilitating symptoms frequently lead to anxiety, depression, decreased quality of life, and frequent hospitalizations. The aim of this study was to examine the impact of an outpatient phone intervention on 30-day hospital readmissions, anxiety, depression, and quality of life in heart failure patients.

Methods: This study used a prospective, longitudinal design to evaluate the effectiveness of a phone intervention for patients discharged with a diagnosis of heart failure. All patients were enrolled at the time of hospital discharge to an outpatient phone monitoring intervention. They received weekly phone calls to assess HF symptoms, and medical compliance. The Minnesota Living with Heart Failure Questionnaire (MLHF-Q) and the Hospital Anxiety and Depression Scale (HADS) were completed at baseline and again after the four week intervention. Data was analyzed using a paired t test. Thirty-day heart failure readmission rates were compared to hospital readmission rates for heart failure patients prior to the intervention.

Results: A total of 33 participants were enrolled in the intervention. The sample ( $\mathrm{N}=33)$ included females $(66.7 \%)$ who were predominantly white $(96.9 \%)$ with a mean age of $75.65 \pm$ 12.36 years. Heart failure type was mainly systolic (51.5\%) with $39.3 \%$ documented as diastolic heart failure. A total of $31(94 \%)$ individuals completed the four week phone intervention. The baseline mean MLHF-Q score was 49. The post intervention mean MLHF-Q score was 14.65 (95\% CI 27.965-40.744,p<0.000). The baseline mean HADS score was 4.26. The post intervention HADS score was 3.00 (95\% CI .274-2.242, $\mathrm{p}=0.014)$. Preprogram facility readmission rate for the primary diagnosis of heart failure was $22.3 \%$. The admission rate for the intervention group was $12 \%$.

Discussion/Conclusion: The results of this study demonstrate the effectiveness of a nurse-led telephone program on quality of life, anxiety, and 30 day readmissions. Further research is needed to establish the efficacy of a telephone intervention on depression, long-term effectiveness, and to identify the usefulness of this type of program for each heart failure functional class. 


\section{Acknowledgements}

This project was the culmination of persistence, determination, and the help from many individuals that I would like to gratefully acknowledge:

- To my committee members Dr. Susan McCrone, Dr. Jennifer Riggs, Dr. Mark Studeny, and Margaret Bowers, thank you for sharing your valuable time and expertise. I would particularly like to express my gratitude to my chair, Dr. Susan McCrone for your dedication and wisdom.

- To the Administration at St. Mary's Medical Center thank you for your assistance and support during this project

- In memory of Ernest F. Leaberry III for showing me the importance of education

- To my father Bill G. Adams for teaching me the value of working hard

- To my mother Willa J. Adams who always said yes when I needed help

- Most of all, to my husband Dr. Jeffrey Leaberry and daughter Addison Leaberry, for your support, patience, and for coming along on this adventure 


\section{Table of Contents}

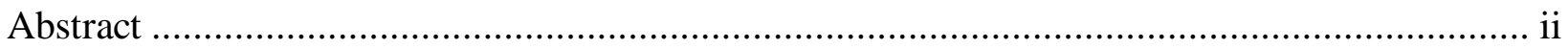

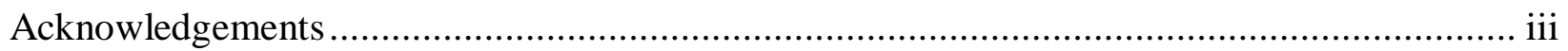

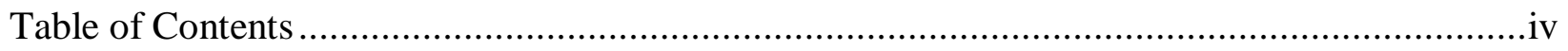

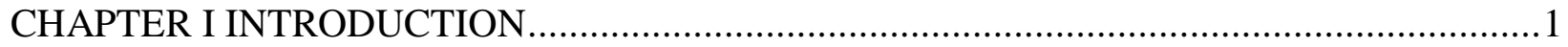

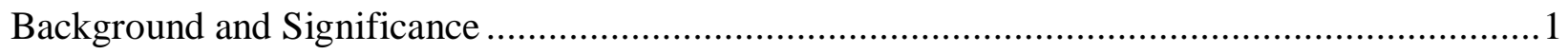

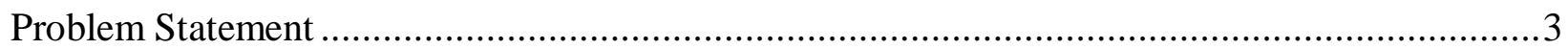

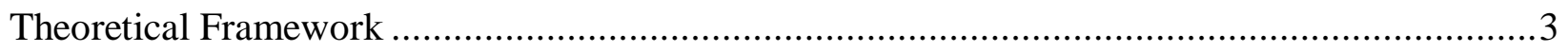

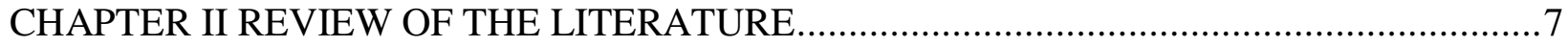

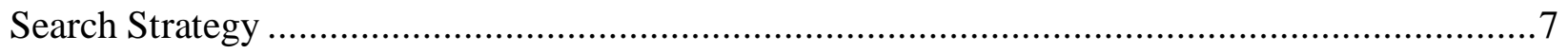

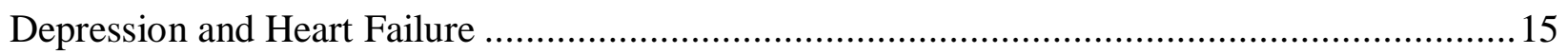

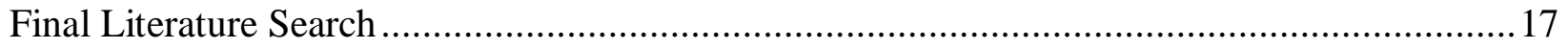

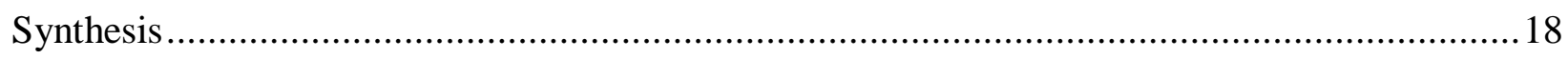

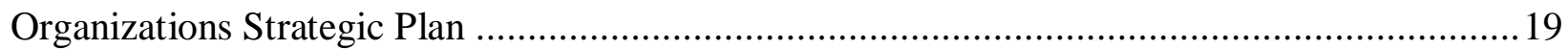

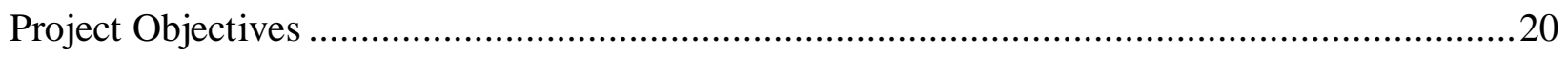

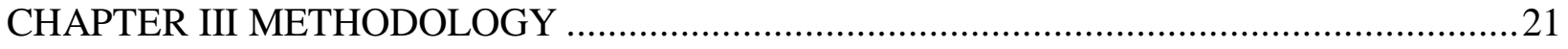

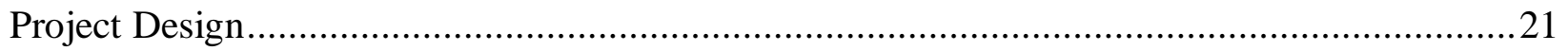

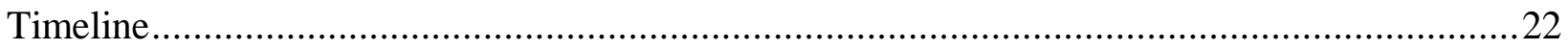

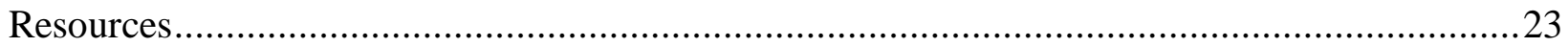

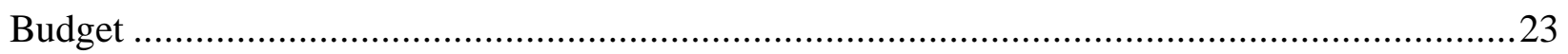

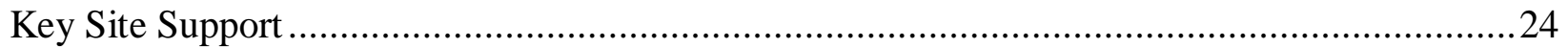

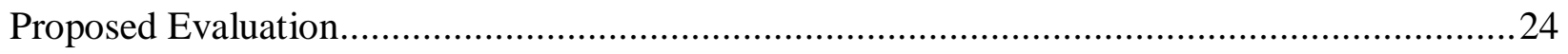

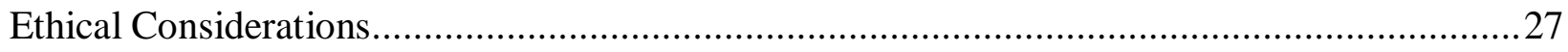




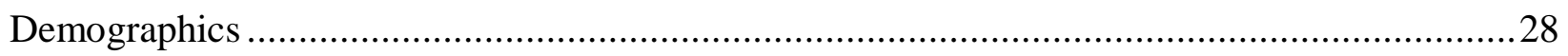

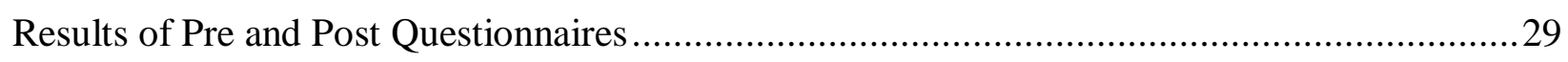

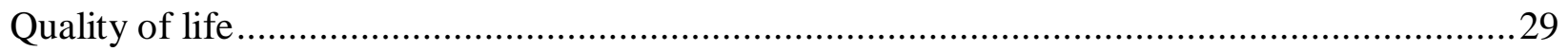

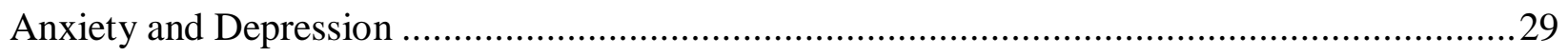

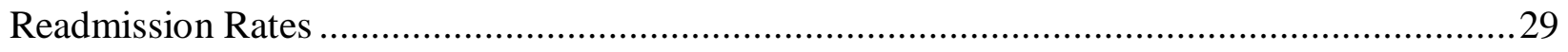

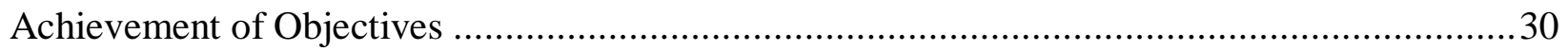

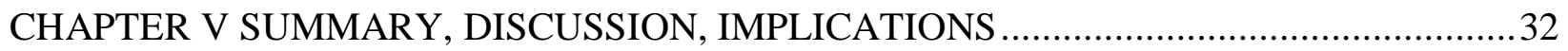

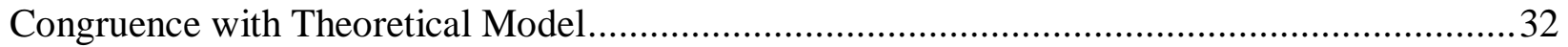

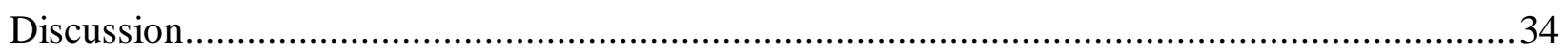

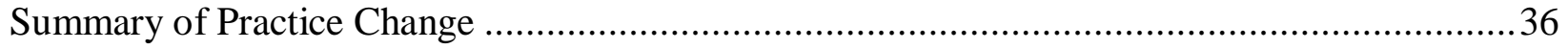

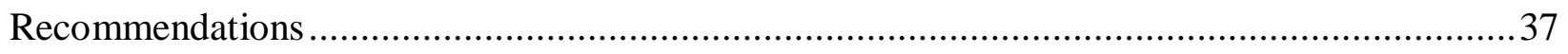

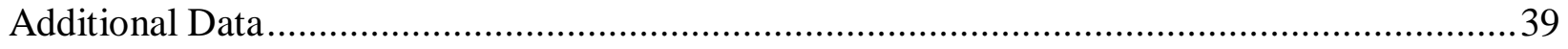

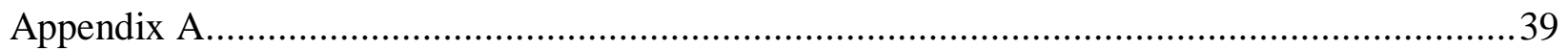

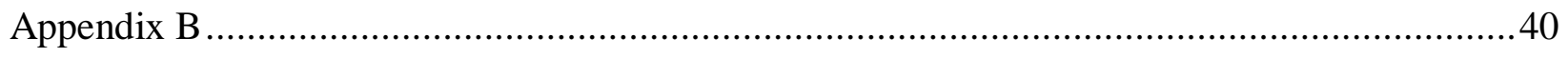

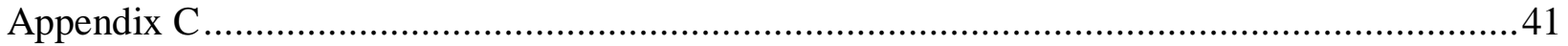

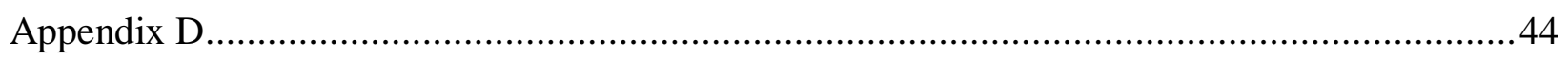

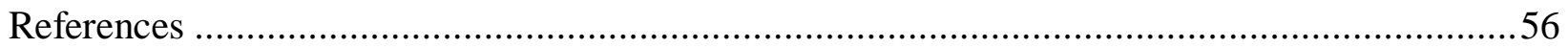




\section{CHAPTER I INTRODUCTION}

\section{Background and Significance}

The prevalence of heart failure has continued to increase around the world over the past thirty years. Heart failure (HF) is generally a chronic process that results in frequent unplanned hospitalizations, increased mortality and an overall reduction in quality of life (Anderson, 2008). According to the American Heart Association (2009), over five million Americans are living with this disease and 550,000 new cases will be diagnosed this year. The disease process is described as a cardiac abnormality where the ventricles are unable to fill or pump blood efficiently. Symptoms of heart failure include shortness of breath, fatigue, lower extremity or abdominal edema, and weight gain. It is most common in the elderly population and is also the most commonly documented Medicare hospital discharge diagnosis (Anderson, 2008). Bakan \&Akyol (2007) estimate over 900,000 individuals will be hospitalized this year with the primary diagnosis of HF. Furthermore, half of the elderly patients diagnosed with HF will be readmitted to the hospital within six months after discharge.

In addition to the physical impact of the disease, the psychological impact of this illness can be overwhelming. Depression and anxiety are frequent complaints of patients with heart failure. Feelings of depression are reported in $15 \%$ to $36 \%$ of individuals with this diagnosis, while anxiety was apparent in $29 \%$ to $45 \%$ (Scherer, 2007). These figures are well above the prevalence noted for the general population. Depressive symptoms are associated with increased hospital readmissions for heart failure exacerbations. Social and family support can assist in decreasing depression symptoms and reducing readmission rates. Nevertheless, depression and anxiety in patients with heart failure frequently remain unaddressed and untreated by health care 
providers (Scherer, 2007). Not only does heart failure impact psychological factors but quality of life as well.

Quality of life is a subjective characteristic of an individual's perception of health function and is frequently altered with heart failure. Shortness of breath, fatigue, and edema are the main symptoms of heart failure which leads to activity intolerance and alters normal living patterns. In addition to these physical symptoms, quality of life is also impacted by depression, anxiety, adverse responses to treatments, social isolation, and frequent hospitalizations. Heart failure patients frequently withdraw from or are physically unable to engage in previous social activities; leading to a loss of social support. The progressive nature of the disease further results in increased dependency on friends and family members, changes in eating habits, changes in sleep patterns, and alterations in intimate relationships (Dunderdale et al., 2004).

The burden of heart disease and heart failure in the state of West Virginia is immense. For the most part, heart failure generally occurs as a result of injury to the heart muscle from a myocardial infarction, long-term uncontrolled blood pressure, or structural dysfunction of the heart valves. Compared to the rest of the United States, individuals who reside in West Virginia have a higher incidence of cardiovascular disease risk factors. According to the West Virginia Department of Health and Human Resources (2002) and the Center for Disease Control (2010), West Virginians report higher levels of hypertension (31.3\% versus $26.2 \%)$, higher cholesterol profiles $(37.1 \%$ versus $16 / 3 \%$ ), and more obesity (31\% versus $26.7 \%)$, diabetes $(11.4 \%$ versus $5.9 \%)$, nicotine dependence (27.1\% versus $24 \%)$, and tooth loss $(37.8 \%$ versus $18.1 \%)$.

At an acute care facility in southwestern West Virginia, there were a total of 444 patients discharged between January 1, 2007 and December 31, 2007. These patients were mostly age 65 and older, Caucasian, and primarily relied on Medicare as an insurance source. These 
individuals represent a total of 2,236 inpatient days and an average of $\$ 9,498.99$ total charges per patient. Patients are treated by either primary care physicians or cardiovascular specialists. Care includes a variety of diagnostic tests and pharmacotherapy delivered at the discretion of the attending physician with the use of clinical pathways designed for inpatient utilization (St. Mary's Medical Center, 2009).

Despite aggressive pharmacologic advances and new heart failure implantable devices, the impact associated with heart failure is both expensive and debilitating (Eliaszadeh, Yarmohammadi, Nawaz, Boukhalil,\& Katz, 2001). Documented one-year survival rates are 57\% in men and $64 \%$ in women and five-year survival rates are as low as $25 \%$ in men and $38 \%$ among both men and women (Eliaszadeh et al., 2001). In the United States alone, it is estimated that total annual heart failure expenditures could reach as high as $\$ 38$ billion. Inpatient costs associated with this disease accounts for over $\$ 8$ billion dollars of that figure and represents more than five million hospital-days annually (Eliaszadeh et al., 2001).Based upon this data, the research question proposed is: In adults with heart failure, what effect does a nurse led telephone intervention have on anxiety, depression, quality of life, and 30 day readmission rates.

\section{Theoretical Framework}

The Roy Adaptation Model (RAM) developed in 1964, defined the primary goal of nursing as a focus on patient adaptation. In 1970, the RAM was first introduced as a framework for nursing theory (Meyers n.d.). During the 1990's Roy identified the importance of re-defining adaptation in preparation for the $21^{\text {st }}$ century. Roy utilized past experience, expanded spirituality, and incorporated new scientific evidence to enhance the definition of adaptation and the philosophical assumptions. Today, the theory is one of the broadest and most widely used of all the nursing theories (Rogers \& Keller, 2009). The RAM emphasizes the interaction between 
the environmental stimulus and the bio-psycho-social reaction to the stimulus. It focuses on the relationship between the individual and the environment as the process of adaptation takes place. Scientific assumptions include: the process of thinking and feeling leads to the awareness of self and environment, human decisions influence the creative process, and harmony between the individual and the environment results in adaptation, acceptance, protection, and levels of interdependence. Philosophical assumptions include: common relationships with the world and a god figure and human accountability for sustaining and changing the universe. Roy emphasizes human creativity with heightened abilities of awareness, enlightenment, and faith. Furthermore, the RAM identifies four adaptive modes including physiologic, self concept, role function, and interdependence which are essential components in maintaining adaptation (Roy, 1997).

Health is defined as a process of interrelating and becoming whole. The theory describes the environment and the person in a reciprocal relationship. The overall goal is to focus on health promotion of individuals and groups through the adaptation process. The process of adaptation is evaluated in physiologic (physical) and psychosocial terms (self-concept, role function and interdependence). The physiologic-physical terms measure the functions of the body. Self-concept evaluates spirituality, beliefs, and feelings. Role function focuses on the expectations and how the patient relates with others. Finally, interdependence measures giving, receiving, and nurturing relationships (Rogers \& Keller, 2009).

RAM has been widely used to guide many areas of nursing care including care for chronic illnesses like heart failure. Bakan \&Akyol (2007) examined the effects of a Roy Adaptation Model-based education, exercise, and social support intervention on adaptation in individuals with heart failure. The study design was a randomized, controlled clinical trial. A 
total of 43 patients with heart failure were randomized to receive usual care or an intervention which included educational materials, counseling sessions, follow-up phone calls, and one group session. The participants were followed for a total of three months. The study concluded that the participants in the intervention group were well adapted to their chronic heart condition. Participants in the intervention group reported increased quality of life with improvement of Minnesota Living with Heart Failure Questionnaire scores (MLHF-Q), increased 6-Minute Walk Test scores, and enhanced social support within the interdependence mode. Overall, the results of the study showed that RAM is an effective tool for guiding nursing practice in individuals with chronic heart failure. Study limitations included a small sample size, and a short period for follow-up, which could potentially limit the power of the study.

The four identified adaptive modes will be used in this study to map the key concepts of the theory and define how these relate to the heart failure intervention. The physiologic-physical adaptation focuses on the importance of five elements of oxygenation, nutrition, elimination, activity, rest, and protection. Essential components of these elements include fluid, electrolyte, acid-base balance, neurologic, and endocrine function. Physiologic-physical adaptation is an important factor in maintaining proper fluid balance of heart failure patients. This adaptive mode was utilized frequently during the heart failure intervention with frequent assessments of fluid status by daily weights, vitals signs, serum lab work, dietary, medication compliance review, and patient's physical symptoms. Established clinical practice guidelines were used in achieving goals set for this adaptive mode. The self-concept-group identity mode describes a psychic and spiritual integrity to establish and maintain a sense of unity, meaning, and purposefulness within the universe. This adaptive mode was demonstrated in the heart failure intervention with weekly phone calls to provide: emotional support, education, answer questions, 
and evaluate quality of life. Role function is an important part of the RAM and also the heart failure intervention. The RAM need is social integrity including role development and role understanding. The heart failure intervention addressed this need during the patient education and weekly phone call sessions. The patient role was clearly defined with clear patient centered goals and expectations. Time was set aside weekly to answer questions and to establish the patient's role in managing his/her disease. Finally, RAM identifies the need for interdependence to achieve integrity. Providing high quality nursing care in the patient's own home through telephone interventions was able to foster a high level of interdependence in patients diagnosed with heart failure. The patient was able to manage his/her illness by recognizing signs of worsening heart failure, eating a proper low salt diet, and taking medications as prescribed. 


\section{CHAPTER II REVIEW OF THE LITERATURE}

\section{Search Strategy}

The search strategy to identify the best evidence related to the use of a nurse led telephone intervention included a search of National Guideline Clearinghouse, Cochrane Library, Academic Search Complete, CINAHL, and PUBMED. Keywords used for the search included outpatient, heart failure, treatment, nurse, and intervention. The initial search of key words outpatient, heart failure, and treatment in the documented databases yielded a total of 1,636 hits. The search was narrowed by the inclusion of peer reviewed journals and clinical trials. This revealed a total of five relevant articles. The search terms were then changed to include nurse led intervention and heart failure. This yielded an additional 76 hits. This was again narrowed by limiting the search to only randomized controlled trials and meta-analyses which yielded a total of 17 articles. A second search was conducted to find additional evidence related to interventions that targeted depression in heart failure. A third search was completed to update the literature at the conclusion of the practice change. Academic Search Complete, CINAHL, and PUBMED were searched using the terms heart failure, phone, intervention, and depression. This yielded an additional 2 articles. A total of 16 relevant articles including two clinical practice guidelines (Hunt et al., 2009; Scottish Intercollegiate Guidelines Network, 2007) three meta-analysis (Clark, Inglis, McAlister, Cleland, \& Stewart., 2007; Iglis et al., 2010 and Klersy et al., 2011) and nine randomized controlled trials (Antonicelli et al., 2008; Bocchi et al., 2008; Dansky, Vasey, \& Bowles, 2008; Gesica Investigators, 2005; Giordano, 2009; Martensson, Stromberg, Dahlstrom, Karlsson, \& Fridlund, 2005; Newman, 2002; Thompson, 2008)one observational study (Scherer, 2007) and one pilot study (Cole et al., 2006) were reviewed. 
A critical appraisal was completed on each of the 16 documents using the appropriate appraisal tool (The Agree Research Trust, 2006; Scottish Intercollegiate Guidelines Network, 2007). The 2009 heart failure clinical practice guideline update (Hunt et al., 2009) focused on the management of heart failure in adults. In this guideline, there was significant evidence that supported the use of comprehensive discharge planning and post discharge home support for an overall reduction in hospital readmission. The guideline objectives and clinical questions were clearly stated and specifically described early in the documentation of the guideline. The systematic methods for evidence search were clear and well documented with a strong link between recommendations and supporting evidence. Databases used for the literature search were clearly defined including Medline and EMBASE and a manual search of selected articles. The target patient population and target users of the guideline are well documented. Health benefits, side effects, and different treatment options were well described. Furthermore, documentation was included that discussed the process of external review, methods for up-dating the guideline, and conflicts of interest among the developing members. Limitations associated with the guideline include the lack of information related to the potential cost of applying the recommendations. There was little information given regarding appropriate criteria for monitoring and audit purposes. In addition, there was limited documentation of supportive tools for application

The Scottish Intercollegiate Guideline Network introduced a national clinical guideline regarding the management of chronic heart failure (Scottish Intercollegiate Guidelines Network, 2007). This guideline emphasized the importance of a nurse led, home based heart failure intervention. The recommendation included post-discharge follow-up over the telephone by a nurse specifically trained in heart failure. The nurse should have the ability to alter diuretic 
doses and schedule emergency provider visits as needed. There was documentation of strong evidence that supported a relationship between home follow-up and a reduction in hospital readmission for heart failure. Strengths of this clinical practice guideline include a well described clinical question and strong documentation of systematic methods used to search for evidence. The methods used for formulating the recommendations and an explicit link between the recommendations were well documented. The recommendations are clear, specific, and easily identifiable. The guideline is supported with tools that would be helpful in the clinical setting. In addition, the procedure for updating the guideline, methods for external review, and health benefits are well described. A weakness associated with the guideline included a lack of involvement regarding the patient's view points. There is little information detailing potential organizational barriers in applying the recommendations. There is no information included that discusses potential cost implications or criteria for monitoring or audit purposes. Furthermore, there is no information included that addresses the funding body of the guideline or information that identifies conflicts of interest among the developing members.

Clark et al. (2007) conducted a meta-analysis of 14 randomized controlled trials to determine whether a telemonitoring initiative without regular clinic or home visits improves care in patients with heart failure. The telemonitoring intervention was a structured telephone followup targeting the identification of symptoms and physiologic data. The results of the study concluded that remote monitoring programs reduce the rates of hospital readmission by $21 \%$ and all cause mortality by $20 \%$. Identified strengths of the study include an appropriate and clearly focused question. An explanation of the methodology was clearly described and well covered. The literature search was rigorous and included relevant, well described studies that were similar 
in nature. Included studies were methodologically sound randomized controlled trials that were judged using accepted criteria and compared with the review protocol.

Antonicelli et al. (2008) conducted a randomized controlled trial to determine the effects of a telemonitoring intervention with elderly patients with heart failure. The telemonitoring intervention included contact by phone once a week and collection of information on HF symptoms, adherence to treatment, blood pressure, heart rate, weight, and urine output. A device was also provided for a weekly electrocardiogram transmission. A total of 57 heart failure patients were randomized to usual care or to a home telemonitoring program and were followed for 12 months. Home telemonitoring was associated with improvements in combined mortality and rate of rehospitalization $(\mathrm{p}=0.006)$. In addition, the intervention group was found to have increased compliance with the treatment plan, increased use of beta-blockers and statins ( $\mathrm{p}<0.03)$, improved cholesterol profiles, and a better overall perception of health $(\mathrm{p}=0.046)$. Strengths associated with this study include the study design randomizing the participants to the intervention or control groups. Study methods were well described with detailed information on inclusion and exclusion criteria. Furthermore, individuals were followed for a 12 month time period. One weakness was that the study enrollment was very low (57 subjects). This was due to strict inclusion criteria which only enrolled $59 \%$ of available heart failure patients.

Bocchi et al. (2008) conducted a similar study to investigate the effects of a disease management program with education and a telephone monitoring program on mortality rates, hospital readmission, and quality of life. The Repetitive Education and Monitoring for Adherence for Heart Failure (REMADHE) trial is described as a long-term, randomized, prospective, parallel, and controlled trial. The telephone monitoring intervention was initiated after the second educational class and was conducted at 14-day intervals. Calls were completed 
by trained heart failure nurses and focused on compliance, signs of worsening heart failure, diuretic adjustment and reinforcement of heart failure education. The object of the telemonitoring intervention was to reinforce HF education, monitor compliance of treatment plan, and to monitor for signs and symptoms of worsening heart failure. The control group received usual care which consisted of ambulatory follow-up treatment under the direction of a cardiologist with heart failure experience. Baseline age for the control group was $52 \pm 11$ and 50 \pm 19 for the intervention group. The results of the study concluded that this intervention under the supervision of a cardiologist is associated with a decrease in hospital readmission $(\mathrm{p}=0.008)$, a decrease in in-patient days $(\mathrm{p}<0.0001)$, a reduction in emergency care visits $(\mathrm{p}<0.0001)$, and an improvement in quality of life using the MLHF-Q $(\mathrm{p}<0.003)$. However, there was no difference in mortality between the groups. Identified study strengths include the overall study design which is described as a prospective, controlled trial. The study was designed to provide longterm follow-up information with a mean of 2.47 years. A detailed description of the study design and selection process of the study population was provided. Limitations of the study were twice as many patients were randomized to the intervention group (233), as were randomized to the control group (117). The study also took place in only one study facility with a multidisciplinary team delivering the intervention which could potentially impact the generalizability of the results.

Dansky et al. (2008) examined the effect of telehomecare on hospitalizations, emergency department visits, mortality, and symptoms associated with heart failure. The investigators designed a prospective, randomized field experiment that consisted of two treatments group and a control group. The telemonitoring intervention consisted of a monitoring system placed in the home for transmission of physiologic data to the health care facility. Two types of monitoring 
systems were used, a one-way model which transmitted physiologic data, and a two-way model with a synchronous video component. The control group received usual care which consisted of home visits only. The study enrolled a total of 284 patients in 10 home health agencies located in one mid-Atlantic state. Patients with the primary or secondary diagnosis of HF who could communicate in English were included in the study. Mean ages of the study groups were 76.9 years in the control group, 76.7 years in the monitor only, and 78.1 years in the monitor/video group. The investigators found that telehomecare reduces heart failure symptoms, decreases hospitalizations, and reduces overall emergency room use. After 60 days, $30 \%$ of the participants in the control group had utilized the emergency room compared to $24 \%$ of the individuals in the monitor group and $18 \%$ in the video intervention. Strengths of this study include the randomized, controlled study design. A detailed description of the methodology and a table of descriptive statistics were provided. In addition, the study used multiple different home health agency sites. A study weakness was a high attrition rate which could potentially impact the statistical power of the study.

In 2005, the Grupo de Estudio de Sobrevida en la Insuficiencia Cardiaca en la Argentina (GESICA) investigators tested whether an organized telephone intervention decreases mortality or hospital admissions for increased heart failure symptoms in an outpatient setting. The telemonitoring intervention included education, counseling, and monitoring by nurses using telephone calls at two week intervals. A randomized, controlled, multi-center design was used to enroll a total of 1,518 outpatients who were diagnosed with stable heart failure. Baseline age of the two groups was 65 years, most were men (71\%), and 80\% had left ventricular systolic dysfunction. The results showed a positive benefit associated with reduction of hospital admission ( $\mathrm{p}=0.026)$ and an increase in the quality of life $(\mathrm{p}=0.001)$. Strengths related to this 
study include the randomized controlled, concealed, blinded, multicenter study design. The inclusion and exclusion criteria were well described. Furthermore, the study had a large enrollment (1518) with $99.5 \%$ of the sample completing the follow-up.

Two other randomized controlled trials were reviewed (Giordano et al. 2009: Thompson et al. 2008), which investigated whether a telemonitoring intervention could decrease events related to heart failure disease. Giordano et al. (2009) used a multicenter, randomized controlled trial involving 460 heart failure patients. The mean ages were 58 years for the home-based group and 56 years for the control group. Documented comorbidities included; myocardial infarction, chronic atrial fibrillation, chronic lung disease, hypertension, stroke, and diabetes. The aim of the study was to determine the effectiveness of a home-based tele-management program in reducing hospital readmissions and hospital costs compared with usual care over a one year period. Before hospital discharge, each patient was educated about heart failure including monitoring blood pressure, daily weights, heart failure symptoms, and dietary restrictions. The patients randomized to usual care were referred to their primary care physicians with a two week appointment and a 12 month appointment with the cardiologist. The telemanagement intervention was a multidisciplinary care approach utilizing a nurse to assess and apply medical interventions over the phone. In addition, a portable device was given to the patient for the purpose of transmitting a one-lead ECG to the monitoring facility. A nurse or doctor was available 24 hours a day, seven days a week to receive the transmitted information. Appointments were scheduled every week to 15 days for patients with moderate to severe heart failure. More frequent appointments were scheduled for patients with signs of possible decompensation. The study concluded that after one year the intervention reduced hospital readmissions $(p=0.0001)$ and subsequent costs for heart failure patients $(p<0.01)$. The strength 
of the study includes the randomized, controlled, and multicenter design. The weakness of the study was that the process of the randomization to interventions was not well described.

Thompson et al. (2008) studied hospital readmissions rates for high risk heart failure patients. The objective of this study was to document the efficacy of a telehome monitoring intervention in decreasing unplanned hospitalizations, improving functional capacity, and increasing quality of life in heart failure patients. The telehome intervention utilized a homebased system for three months of video conferencing, daily transmission of weight and vital signs, and a periodic transmission of a 12-lead ECG. The control group received usual care. A total of 249 patients were enrolled in this randomized controlled trial. The mean age of the patients was 66 years. Seventy-five percent of these individuals were males who had a history of symptomatic heart failure or angina. The results of the study indicated that telehome monitoring reduced total hospital readmissions and improved quality of life. A strength of this study was the study design, which was a randomized, controlled, and concealed trial that included a one year follow-up period. It also included a patient follow-up rate of $94 \%$.

Newman (2002) examined the effects of a nurse-led intervention to reduce hospital readmissions in patients with documented heart failure. The aim of the study was to plan home visits and telephone contact to educate patients about heart failure, maximize medical management, monitor electrolytes, teach home-monitoring, encourage treatment compliance, and to provide support. The telephone contact was completed by a specialist nurse to obtain heart failure symptoms, vital signs, and weights. A total of 165 patients admitted on an emergency basis with heart failure symptoms caused by left ventricular systolic dysfunction were enrolled in a single center, randomized controlled trial and were followed for one year. Eighty-four patients were randomized to a specialist intervention which included home visits and telephone contact. 
The control group was provided with usual care only. The results of the study showed fewer hospital readmissions for heart failure symptoms (intervention group 14\% verses usual care $32 \%)$. The strength of this study was the design which was a randomized, controlled trial that included a 1 year follow-up. In addition, the study had a high follow-up rate of $95 \%$. Weaknesses of this study include: a small enrollment group of only a total of 165 patients, inclusion and exclusion criteria were not well described, and data was conducted from only a single center setting limiting its generalizability.

\section{Anxiety, Depression, and Heart Failure}

Three studies (Cole et al., 2006; Martensson et al., 2005; Scherer, 2007) examined the efficacy of a nurse-led intervention for the management of anxiety and depression associated with heart failure. Cole et al (2006) evaluated the usefulness of a telephone nurse for the management of patients with depression and congestive heart failure. A total of 24 patients with depression and heart failure were entered into a 13-month telephone disease management intervention. Patient characteristics include mean age of 73.8 years with $57 \%$ of participants being female. The intervention included six elements of the chronic illness care model including the delivery system design, decision support, patient self-management support, clinical information systems, organizational support, and community linkages. The Hospital Anxiety and Depression Scale was administered by a nurse over the telephone for monitoring depression outcomes. The initial telephone call was used to establish the relationship, assess compliance with the treatment plan, and evaluate side effects of prescribed medications. Phone calls were made at least monthly with the administration of a Patient Health Questionnaire (PHQ) and critical patient results obtained during the call were immediately sent to the patient's physician. Results of the study showed an improvement in mean PHQ scores at 24 weeks $(\mathrm{p}<0.0003)$. 
Mean PHQ scores also improved in patients with a history of major depression and other depressive symptoms at 24 weeks $(\mathrm{p}<0.01)$. Weaknesses of this study include a small group of participants in the study (24) and the absence of a control group.

Martensson et al. (2005) conducted a randomized controlled trial to determine the effectiveness of a nurse-led intervention aimed at improving quality of life and depression in heart failure patients. A total of 153 patients were randomized to receive the nurse-led intervention or usual care. Mean age of the participants was $79 \pm 7$ years and the majority (54\%) of these individuals was male. The intervention included a heart failure educational program, monthly nurse-initiated telephone contact to discuss worsening heart failure symptoms and medication side effects, and home visits to administer the SF-36 health survey, MLHF-Q and the Zung Self-rating Depression Scale questionnaires. The frequency of telephone contact and home visits were increased when worsening symptoms of heart failure was determined. The results of the study showed 3-month and 12-month follow-up physical functioning ( $\mathrm{p}=0.035$ and $\mathrm{p}=0.001$ ), emotional limitations ( $\mathrm{p}=0.001$ and $\mathrm{p}=0.022)$, and mental component summary $(\mathrm{p}=0.017$ and $\mathrm{p}=0.0470$ ) were improved. Strengths of this study include the randomized study design and multiple study sites. A limitation of this study is the small sample size of only 153 participants.

Scherer (2007) analyzed anxiety and depression in heart failure patients to identify psychosocial factors and strategies, which positively impact anxiety and depressive symptoms. A total of 291 primary care patients diagnosed with heart failure were enrolled in a longitudinal observation study. Anxiety and depression, quality of life, coping skills, social support, and New York Heart Failure Classification were assessed with a variety of questionnaires at baseline and again in 9 months for each patient. The results showed 211 participants were not distressed at baseline and 80 individuals were distressed at baseline. Of the 80 individuals, $26(32.5 \%)$ had a 
reduced HADS in 9 months $(\mathrm{p}<0.000)$. It was found that interventions providing high social support were the only independent predictor which reduced anxiety and depressive symptoms.

\section{Final Literature Search}

A third literature search was completed in the early summer of 2011 to update the literature in preparation to finalize the practice change. A total of three relevant articles were found which provided additional information in support of the practice change and discussed the economic impact of monitoring patients remotely.

Ferranteet.al. (2010) studied the long-term effects after a randomized trial of telephone intervention to improve education and compliance in heart failure patients (the DIAL trial). The objective of the study was to assess the death rate and hospitalization at 1 and 3 years. A total of 1,518 participants in the original trial were followed after completion for up to three years to assess outcomes. Compliance with the medical plan of care including diet, weight control and treatment was evaluated. The results showed that mortality and heart failure hospital admissions were lower in the intervention group $(\mathrm{p}=0.013)$ at 1 and 3 years after the original intervention. The reduction was mainly attributed to a decrease in hospital readmissions for heart failure.

Inglis et al. (2010) conducted a systematic review to determine the effectiveness of structured telephone support or telemotoring program compared to usual care for heart failure patients. Multiple data bases were reviewed to find peer reviewed randomized controlled trials from 2006 to 2008. A total of twenty-five studies and five abstracts which included 8,323 participants were included. The results showed telemonitoring decreased mortality $(\mathrm{p}<0.001)$ and both structured telephone support $(\mathrm{p}<0.0001)$ andtelemonitoring $(\mathrm{p}=0.008)$ reduced heart failure hospital admissions. The authors concluded that both telephone support and telemonitoring are effective tools in the managing chronic heart failure. 
In 2011, Klersy and colleagues analyzed the economic impact of remote patient monitoring for heart failure. A meta-analysis of randomized controlled trials of 5,715 participants found lower hospitalizations for heart failure patients as a result of remote patient monitoring $(\mathrm{p}<0.001)$. Direct costs for heart failure care were then approximated for these 5,715 patients. The study demonstrated cost effectiveness associated with clinical superiority in the remote monitoring cases. The author's encouraged the acceptance of remote monitoring among providers of heart failure care.

\section{Synthesis}

Evidence collected through the evaluation of 16 documents including: two clinical practice guidelines (Hunt et al. 2009: Scottish Intercollegiate Guidelines Network, 2007),three meta-analysies (Clark et al., 2007, Iglis et al., 2010,Klersy et al., 2011),nine randomized controlled trials (Antonicelli et al., 2008, Bocchi et al., 2008, Dansky et al., 2008, Ferrante et al., 2010, Gesica Investigators, 2006; Giordano et al., 2009; Martensson et al., 2005; Newman, 2002; and Thompson, 2009),one observational study (Scherer, 2007), and one pilot study (Cole et al., 2006) supports the use of a nurse-led phone intervention to decrease hospital readmissions, increase quality of life, and decrease depression in heart failure patients. Heterogeneity was present across studies for the type of telemonitoring used and for outcomes including decreased all-cause mortality and quality of life. The differences in outcomes were mainly attributed to differences in patient age, differences in treatment protocols, and differences in the focus of the study designs. Antonicelli et al. (2008) states that some limitations may be associated with the outcomes due to the fact that the heart failure therapy was not up to date with the current guidelines at the time of data collection. This fact could lead to differences in documented outcomes across studies. However, most of the studies did not address medical management 
protocols in detail. Gaps in the evidence do remain about gender specific and long-term outcomes associated with a telephone intervention. Further research is warranted in these areas to provide strong evidence to guide practice. Fourteen out of 16 data sources reviewed provide strong evidence to support a practice change related to a home telemonitoring intervention to reduce 30-day hospital readmission for heart failure. Therefore, the goal of this capstone project was to evaluate the impact of a nurse-led telephone intervention with heart failure patients on quality of life, anxiety, depression, and 30-day hospital readmissions.

\section{Organizations Strategic Plan}

This acute care facility in southwestern West Virginia began the tradition of caring in 1924. The foundation is built upon the tradition of faith, hope, healing, service, and caring. According to the website (SMMC, 2008), the mission statement involves providing quality health care. The mission statement reads:

We are inspired by the love of Christ to provide quality health care in ways which respect the God-given dignity of each person and the sacredness of human life.

The values are the guiding principles of care. These include compassion, hospitality, reverence, interdependence, stewardship, and trust. Each of these values is an integral component of this program including providing evidence based care from a collaborative approach and with utmost respect to patients, resources, and finances. In addition, the recent strategic plan of this facility aims to assess product-lines in effort to provide quality care, decrease length of stay, decrease costs, and decrease readmissions when possible. 


\section{Project Objectives}

There were four major objectives for this heart failure intervention. The first objective was to increase quality of life as measured by the Minnesota Living with Heart Failure Questionnaire from baseline to 30 days following program enrollment. The second was to decrease anxiety associated with living with heart failure from baseline to 30 days following program enrollment. The third was to decrease depression associated with living with heart failure from baseline to 30 days following program enrollment. The fourth was to reduce 30 -day hospital readmissions for the primary diagnosis of heart failure. 


\section{CHAPTER III METHODOLOGY}

\section{Project Design}

The project utilized a descriptive, prospective, longitudinal study design to investigate the impact of the telephone intervention. Each patient with the primary admission diagnosis of heart failure was captured in the heart failure database. Planned activities include medical evaluation by the Heart Failure Nurse Practitioner to establish continuity of care and for discharge planning. Patients were managed according to the 2009 Heart Failure Clinical Practice Guidelines (Hunt et al., 2009) (Appendix A). At this time, additional services were obtained as necessary and medications were optimized. Past heart failure decompensations were evaluated. Patients admitted to the University Cardiovascular Services were utilized for this study. Inclusion criteria for study participation were patients admitted with acute or chronic heart failure decompensation. Patients excluded from this study were patients with a history of heart failure who were admitted to this facility for reasons other than heart failure. Appropriate patients signed consent forms and were enrolled in the program. In addition to these activities, patient education and medical management were continued as usual. At the time of hospital discharge, the Minnesota Living with Heart Failure Questionnaire (MLHF-Q) (Rector \& Cohn, 2005) and the Hospital Anxiety and Depression Scale (HADS)(Zigmond \&Snaith, 1983) were verbally administered to each participant by the Heart Failure Nurse Practitioner. Patient education was given regarding heart failure and planned home care was provided as part of routine care.

(Appendix B). The working day following discharge, the patient was contacted at home by the Heart Failure Nurse Practitioner to provide time to answer questions and to evaluate health status and heart failure symptoms. The patient were called weekly for a period of four weeks to review daily weights, review medication and dietary compliance, determine heart failure symptoms, and 
for patient education (Appendix C). Participants were contacted more frequently if heart failure symptoms had increased. In addition, patients were scheduled for outpatient clinic visits with the heart failure team in the event heart failure symptoms had increased. The patients were scheduled regular office visits with their private health care provider per the provider's schedule. At the end of 30 days, the MLHF-Q and HADS questionnaires were read to the patient over the phone by the Heart Failure Nurse Practitioner.

The planned program outputs were determined in the spring of 2009 by reviewing frequency of hospital admissions. According to the hospital data, there were 444 patients admitted to this facility in 2007 with the primary diagnosis of heart failure. The planned outcomes were changes in provider practices in care, education and follow-up related to the treatment of heart failure. The aim of the program was to utilize an aggressive team approach to disease management related to chronic heart failure care. The overall program impact is a perceived increase in quality of life, a decrease in anxiety and depressive symptoms, and a reduction in 30-day rehospitalization rate in this patient population.

\section{Timeline}

The first phase of the project began with the literature review that was conducted in the fall of 2009. The organizational phase of the project began in January when the project started to become more finalized. Below is the revised project timeline.

1. Second protocol revision completed and submitted to Capstone Chair September, 2010

2. Completed protocol distributed to Capstone Committee October, 2010

3. Capstone presentation November 1, 2010

4. IRB Approval: Complete appropriate paperwork for IRB approval. Submit by December, 2010. 
5. Capstone practice change begin enrolling patients February 15, 2011

6. Stopped enrolling patients April 30, 2011 with data collection completed by May 15, 2011

7. In-patient Heart Failure Team: Continue to meet with in-patient heart failure team to collaborate in-patient and out-patient projects and to continue to obtain heart failure information and readmission statistics. Ongoing/As scheduled.

\section{Resources}

The Hospital Information Systems Department designed and constructed the Heart Failure Database. This database utilized existing hospital information software and computer systems to flag and store patient information in data files for organization. The Heart Center clinic space was utilized for outpatient visits. Patient exam rooms, exam tables, blood pressure supplies, weight scales, phone, EKG machine, and computerswere already in existence and were available for use for this program. Diagnostic testing and lab work were ordered and obtained in the regular outpatient fashion as needed. One unit secretary was already employed to greet patients in the clinic area. A medical director and one nurse practitioner were available to manage the outpatients and coordinate care for this program.

\section{Budget}

An initial operational start-up cost involved salary expenses including nurse practitioner and medical assistant costs. This is projected at $\$ 170,000$ annually including benefits. Items were budgeted in the 2010 Operational and Capital Budgets to meet these needs. However, after discussions with the Heart Center Director and the Director of Cardiovascular Services, it was decided to operate initial development of the program from a budget neutral platform. Costs of this revised budget are documented in Appendix D. Budgeted items for this project will be requested again in the 2011 budget. Items represented in the revised project budget include daily 
operational needs including paper use, postage, and utilities. Personnel budget items are portions of existing staffing that will be utilized from other areas to carry out the needs of the heart failure project.

\section{Key Site Support}

The project has full administrative support and involvement from the medical team. In addition, the project has several built in alternative project plans to overcome future obstacles. A business plan was developed in the spring of 2009 to assess the need and feasibility of a heart failure project. At that time, the business plan was submitted to the Medical Center as a suggestion for a future project. Funding was placed in the 2010 budget for equipment and staffing as a result of this business plan. A literature search was conducted in the fall of 2009 that indicated strong evidence in support of a nurse-led telemonitoring heart failure project. Heart failure is the most common Medicare hospital discharge diagnosis and most common reason for hospital readmission for the elderly population at this facility. The 30-day hospital readmission rate for this particular facility was $19.3 \%$. This project was predicted to improve care and quality of life, and decrease hospital readmissions, anxiety, and depression associated with the primary diagnosis of heart failure.

\section{Proposed Evaluation}

The project was be evaluated with hospital data for 30-day readmission rates for the primary heart failure diagnosis. These were calculated by the facility and were provided for use. Patients enrolled in the intervention who were readmitted to a different in-patient facility were calculated into the 30-day readmission rate. The previous month hospital readmission rate provided by the facility was utilized for comparison. A Pearson Chi-Square was utilized to determine the significance of the information. Further evidence-based measures will be applied 
using the Minnesota Living with Heart Failure Questionnaire (MLHF-Q) (Rector, 2005)

(Appendix E).

\section{Instruments}

The MLHF-Q was developed in 1984 to evaluate heart failure and the impact of the treatments for heart failure on an individual's quality of life. Questions were designed using key elements of physical, emotional, social, and mental to assess quality of life. The questionnaire uses a 0-5 point system to evaluate heart failure system, limitations, and anxiety level. There are 21 questions that are individually rated and totaled at the end of the questionnaire. Scores can potentially range from 0 to 105 , with the largest number demonstrating the greatest burden of the illness related to quality of life (Rector, 2005). In 1992, Rector and Cohn assessed the reliability and validity of this tool. The study utilized a randomized, double-blind controlled trial to study patient outcomes using the MLHF-Q. Investigators concluded the tool is both highly reliable and valid in assessing quality of life in heart failure patients. In a similar study, Morcillo, Aguado, Delas, \&Rosell (2007) found the MLHF-Q instrument useful in evaluating functional capacity in heart failure patients. The results showed the tool correlated well with functional class and with the patients' disease progress. In addition, the tool was able to detect changes in the patients overall health status. Parajon et al. (2006) studied quality of life in heart failure patients using the MLHF-Q in Spain. Here, the questionnaire was found to have a strong correlation between questionnaire score and the patient's overall functional capacity. This suggests that the questionnaire can adequately evaluate quality of life. Middel \& Bouma (2001) studied the psychometric properties of the MLHF-Q. They concluded the MLHF-Q is an effective tool to measure anxiety related symptoms in cardiac patients. According to Rector (2005), the MLHF-Q scores have also been reliable in studies where data collection was completed over the telephone. 
The MLHF-Q will be used to evaluate quality of life. A paired t-test will be utilized for statistical analysis. Upon discharge from the acute care facility, each patient will be read the MLHF-Q. The questionnaire will be repeated in 30 days over the phone. The results will be compiled and compared to the initial questionnaire.

The Hospital Anxiety and Depression Scale (HADS) (Appendix F) was developed in 1983 to evaluate generalized anxiety and major depressive disorders in the hospital or clinic settings. It utilizes 14 questions to describe the individual's current feelings on a scale of 0 to 3 . Seven questions focus on anxiety and seven questions are dedicated to depression. The responses are calculated with an anxiety score of 0 to 21 and a depression score of 0 to 21 . A depression or anxiety score greater than 11 is considered abnormal (Zigmond \& Snaith, 1983). In 2005, Olsson, Mykleton, \& Dahl evaluated the psychometric features of the tool. A crosssectional survey of 1,781 participants was completed in Norway. The author's concluded that the instrument accurately classified both anxiety (sensitivity 0.89 , specificity 0.75 ) and depressive disorders (sensitivity 0.80 , specificity 0.88 ) with a cut-off score of $\geq 8$. This tool will be used to assess anxiety and depression in heart failure patients. It will be verbally administered to participants upon hospital discharge and again in 30 days over the phone. Any in-patient with an anxiety or depression score greater than ten will be referred to the hospital based counseling team for an evaluation before discharge. An out-patient with an anxiety or depression score greater than ten will be scheduled a heart failure clinic visit and will be evaluated by the hospital counseling team. A paired t-test will be utilized to analyze the data. An overall HADS score will be provided, as well as a separate subscale score for anxiety and depression. 


\section{Ethical Considerations}

The protocol was approved by the Marshall University Medical Institutional Review Board. Vulnerable populations including women who were pregnant and prisoners were excluded as participants. An informed consent (Appendix G) was developed and signed by each participant. Research documents were kept locked and private under the privacy guidelines as adapted by the medical facility. 


\section{Chapter IV Results}

\section{Demographics}

A daily list of possible participants was provided by the facility and patient charts were reviewed for appropriateness. Patients with the discharge diagnosis of congestive heart failure, systolic or diastolic heart failure were enrolled in preparation for discharge. There were a total of 142 patients with the primary discharge diagnosis of heart failure between February 15, 2011 and April 30, 2011. Thirty-five patients met the inclusion criteria. The majority of individuals who did not meet the enrollment criteria included individuals admitted to the non-participating cardiology group. Other individuals not enrolled were individuals who were unable to talk on the telephone, had severe dementia, or were in long-term care facilities. Thirty-three patients were enrolled in the practice change and two individuals declined to participate. The sample $(\mathrm{N}=33)$ included females $(66.7 \%)$ and males $(33.3 \%)$ who were predominantly white $(96.9 \%)$ with a mean age of $75.65 \pm 12.36$ years old. Heart failure type was mainly systolic $(51.5 \%)$ with $39.3 \%$ documented as diastolic heart failure. There was a total of $9 \%$ (4 patients) of the individuals who did not have a documented heart failure type.

The project included 91 completed interventions with a total of 184 phone calls. Interventions included providing scales for daily weights, scheduling follow-up appointments, medication changes, unscheduled clinic visits, unscheduled phone calls, reassessments, emotional support, and education. A total of 31 individuals completed the 4 week phone intervention and the pre and post questionnaires. Two individuals were lost to follow-up due to technical phone issues and there was one death outside of the 30-day follow-up period. 


\section{Quality of life}

A Minnesota Living the Heart Failure Questionnaire was completed at baseline and post telephone intervention. There was a significant decrease in the MLHF-Q indicating an improvement in quality of life. The baseline mean MLHF-Q score for all participants was 49. The post intervention mean MLHF-Q score was 14.65 (95\% CI 27.965-40.744 p<0.000).

\section{Anxiety and Depression}

The Hospital Anxiety and Depression Questionnaire was administered at baseline and post telephone intervention. There was a significant decrease from pre to post test. Baseline scores ranged from 0 to 10 and post intervention scores ranged from 0 to 8 . The baseline mean HADS score was 4.26 while the post test was 3.03 (95\% CI .274-2.242p=0.016). The HADS questionnaire was developed to measure anxiety and depression simultaneously. There are seven questions to identify anxiety and seven questions to determine depression. These sub-scales

were also analyzed separately. Questions 1, 3, 5, 7, 9, 11, and 13 identified anxiety. The mean baseline anxiety score was 2.23 and the post test score was 1.23 . There was a statistically significant difference in these scores (95\% CI .508-1.492 p <0.000). Question 2, 4, 6, 8, 10, 12, and 14 were depression items. The baseline mean depression score was 1.90 and post test score was $1.84(95 \%$ CI .650-.779 p=0.855).

\section{Readmission Rates}

Preprogram facility readmission rate for the primary diagnosis of heart failure was $22.3 \%$. Program readmission rates were decreased to $12 \%$. This is a $46.2 \%$ reduction in readmission rates indicating a major reduction (Chi-Square with one degree of freedom $=1.675$, $\mathrm{p}=0.196)$. 


\section{Achievement of Objectives}

There were four main objectives associated with this practice change. One objective was to reduce 30-day hospital readmissions for the primary diagnosis of heart failure. Hospital readmission rates were obtained just prior to beginning enrollment. The facility overall heart failure rate had increased since the previous measurement and was calculated at $22.3 \%$. There were a total of four hospital readmissions associated with the telephone program. This included two males and two females. Out of the four readmissions, at least two of the readmissions potentially could have been avoided. All four patients were readmitted within the first week after discharge. Keeping close contact with patients by increasing the number of phone calls for changes in weight and symptoms was most helpful in reducing the readmission rate. There were also many unintended activities that were completed in order to give these individuals the best care and service. These activities included obtaining patient education booklets for device implants and appointments for device follow-up, notifying the medical provider for an elevated international normalized ratio, notifying the medical provider for a patient with a stent who had stopped antiplatelet medication, and coordination of care between services. Barriers to reducing readmission rates with a telephone program include making adjustments in the medical plan of care usually based on the data provided by the patient without always actively examining the patient.

Another objective is patients enrolled in the heart failure intervention will indicate increased quality of life 30 days following program enrollment. In multiple studies, the MLHF$\mathrm{Q}$ is found to be both highly reliable and valid in assessing quality of life in heart failure patients. In addition, the instrument has been deemed useful in evaluating functional capacity in heart 
failure patients. There was a significant difference in pre and post total MLHF-Q scores $(p<0.000)$ related to quality of life. At times, the longer length of the questionnaire was a barrier in this project due to the fact that these patients would tire easily.

There were also objectives to decrease anxiety and depression associated with living with heart failure 30 days following program enrollment. The HADS questionnaire was used to evaluate the psychological symptoms of anxiety and depression. The questionnaire has two possible subscales ranging from 0 to 21 . A subscale score of 10 or greater for anxiety or depression is considered abnormal. There was a statistical significance in the difference in the baseline (4.26) and post intervention (3.03) total HADS scores $(\mathrm{p}=0.016)$. The analysis of the subscales showed a statistically significant improvement in anxiety scores $(\mathrm{p}<0.000)$. There was no significant improvement in the depression subscale $(\mathrm{p}=0.855)$. A total of four participants were found to have a total HADS score greater than 8 . There were no individuals who had an elevated pre or post anxiety or depression subscale score. Therefore, no referrals for counseling were necessary. The pre and post total HADS scores shows strong evidence a phone call program can decrease anxiety related to chronic heart failure.

There were also psychological questions associated with the MLHF-Q. Questions 19, 20, and 21 identify anxiety and depression related to living with heart failure. Mean baseline scores of question 19 (making you worry) were 1.84 and post intervention mean score was 0.45 . Mean baseline score of sub-scale question 20 (making it difficult to concentrate) were 1.32 and post test score was 0.35. Question 21 (making you feel depressed) was 1.16 and post intervention score was .35. Mean baseline score ofthe baseline and post test HADS scores along with the psychological questions of the MLHF-Q shows strong evidence that a phone call program can decrease anxiety and depression related to chronic heart failure. 


\section{CHAPTER V SUMMARY, DISCUSSIONS, IMPLICATIONS}

\section{Congruence with Theoretical Model}

The Roy Adaptation Model (RAM) is the framework utilized to guide this practice change. The key element of this model is human beings are able to positively adapt to their environment as necessary to maintain a balance in health. There are four modes of adaptation humans maintain to assist with the adaptive process including physiologic, self concept, role function, and interdependence. Management strategies were developed to address each of these modes during the interactions with the participants. Assessment of this adaptive mode occurred during five main points during the project. These points include the initial contact when the pretests were completed and with each of the four phone calls. However, phone calls and other participant contact were increased as heart failure symptoms and participant weight increased. Patients were scheduled a same day or next day clinic appointment for weight increases by two pounds in 1 day or five pounds in 1 week. After medications were adjusted for an increase in symptoms, patients were contacted the next day over the phone to see if symptoms had improved. Patients with general complaints which were not specific indications of worsening heart failure symptoms were contacted by phone within the same week to see if symptoms had improved.

The physiologic-physical adaptive mode of the RAM is perhaps one of the most important aspects related to heart failure. The individual need is highly related to oxygenation, nutrition, elimination, activity, and protection. This adaptive mode is altered in response to the acute and chronic physiologic processes of heart failure. These processes associated with this mode include fluid, electrolyte and acid-base balance. Monitoring daily weights and heart failure symptoms was one of the key elements of this project. An increase in weight or an 
increase in symptoms such as shortness of breath and edema prompted an increase in assessment and a potential change in the medical management regimen.

Self-concept-group identity is also an important part of the RAM. This mode describes a psychic and spiritual need to maintain a sense of meaning and purpose. The RAM emphasizes shared relations, goal development, and achievement as an integral part of the process of adaptation. Frequent participant contact provided needed emotional support and educational activities related to this chronic disease. Participants generally embraced the opportunity to receive information and to ask questions.

Role function is identified in the RAM as social integrity including role development and understanding. Changes in roles frequently develop in the social support systems of chronic heart failure patients. Often, patients are not able to function in the same capacity triggering family members to take over important duties within the family unit. Heart failure patients need additional support and education to determine activities they can master and where they now fit in their family and social groups. Providing additional education and frequent phone contact assisted in addressing the mode.

Finally, the RAM identifies the need for interdependence to achieve integrity. Providing high quality evidence-based nursing care over the telephone allowed necessary support for participants to return home and assist in managing their own care. Providing a 24 hour contact return telephone number also allowed the participant to call for assistance when necessary.

The RAM provided a framework that identified adaptation modes, which were useful in successfully managing patients with heart failure. The modes can also be an effective guide in evaluating the adaptive process to this chronic disease. 


\section{Discussion}

The majority of objectives associated with this project, reducing hospital readmissions, decreasing anxiety, and increasing quality of life associated with heart failure were attained as evidenced by a decreased hospital readmission rate, improved HADS scores and decreased MLHF-Q scores. The mean sub-scales for anxiety on the HADS were decreased from 2.23 to 1.23 . The mean MLHF-Q scores were reduced from 49 to 14.65 indicating an increase in quality of life. There was a $46.2 \%$ reduction in 30 day hospital readmission rate for heart failure. It is important to note decreasing MLHF-Q scores could have been a reflection of continued improvement of the individual health status following an acute exacerbation of heart failure and not necessarily a direct benefit from the phone calls. One way to have controlled for this would be to randomize to a control group. Enrolling participants at their baseline functioning instead of after an acute event would also help to tease out the benefit of frequent contact. Obtaining additional data collection at 3 months, 6 months, and 1 year would also to help establish the long-term benefit.

The positive impact of a telephone program on depression was not demonstrated in the analysis of the HADS depression sub-scales. For the most part, the mean pre program scores were not elevated indicating depression was not a baseline issue. The length of the program and the fact participants were continuing to make adjustments to their medical management and lifestyle plans could have also impacted this outcome. However, there was an improvement in the sub-scale questions contained in the MLHF-Q which indicated a phone intervention did positively impact depression related to heart failure.

A limitation to this study is sample size. Despite aggressive efforts to recruit appropriate heart failure participants, only 33 individuals were enrolled in the program. There were at least 
four individuals that met the inclusion criteria but were not enrolled because transfers to outside facilities for advanced heart failure care or surgical procedures. The final sample size was 31 participants at the final stage of the program. Two individuals completed the initial questionnaires and received a total of two to three telephone calls before their phone was unreachable. The small number of participants could positively impact the statistical power of the study.

A second limitation is the severity level of heart failure was not documented for each patient. This study included patients that represented mild to end-stage heart failure. Patients with more severe heart failure are more frequently admitted to acute care facilities with heart failure exacerbations and have an increase in heart failure symptoms. Providing this information would have provided additional information regarding the heart failure class which is most appropriate for telephone monitoring.

A third limitation to this program was there was no random assignment to control group associated with this practice change design. This would have further enhanced the rigor of this project.

This intervention is consistent with the findings of similar studies of telephone monitoring programs found in the literature. The literature showed a reduced risk of heart failure related mortality, a reduction in heart failure related hospital admissions, reduction in anxiety and depression, and an improvement in quality of life. There were multiple studies resulting in a significant reduction in hospital readmissions with a telephone intervention for heart failure. Clark et al. (2007)showed a 21\% reduction in hospital readmissions with a remote telemonitoring intervention. Antonicellie et al. (2008), Bocchi et al. (2008), and Dansky et al. (2008) found significant reductions in heart failure rehospitalizations in similar studies. GESICA investigators 
(2005) showed a reduction in heart failure symptoms resulting in decreased hospital readmissions. Ferrante et al. (2010) studied the long-term effects of the GESICA study and confirmed a decrease in heart failure rehospitalizations after 1 and 3 years.

This study was also consistent with the positive findings in the literature for quality of life associated with heart failure. Several studies showed significant improvements in quality of life following an organized phone intervention after hospital discharge. Bocchi et al. (2008) and Martensson et al. (2005) showed improvements in MLHF-Q scores following and organized phone intervention. While Dansky et al. (2008), GESICA (2005), and Thompson et al. (2008) documented reduced heart failure symptoms with telemonitoring.

There were also multiple studies found in the literature which evaluated anxiety and depression associated with heart failure. The study conducted by Scherer in 2007 resulted in reduced HADS scores with increased social support. This is consistent with the results found in this intervention. Cole et al. (2006), and Martensson et al. (2005) found a decreased in depressive symptoms following a telephone intervention. Differences were found in this study related to depression. Inconsistencies were found across the different assessment tools (HADS and MLHF-Q) for the efficacy of a phone intervention to decrease depressive symptoms in heart failure patients. However, this study contributes further evidence for the usefulness a structured phone intervention for the management of heart failure.

\section{Summary of Practice Change}

The objectives for this practice change associated with quality of life, anxiety, and readmissions were attained. There was inconsistence evidence in support of a telephone intervention for depression. There were no significant adverse events associated with the practice change. 
Generally, the participants welcomed the assistance, were responsive to the questionnaires, and regularly answered the telephone. The facility administration was supportive, offered assistance, and made changes in hospital protocols as necessary. Other stakeholders such as physicians evaluated participants, made recommendations to the medical regimen, and interpreted diagnostic testing as needed.

This information adds to the documented evidence that a telephone monitoring program has positive benefits associated with heart failure. The post heart failure questionnaire shows frequent follow-up can decrease heart failure associated anxiety and can improve functional capacity. Frequently monitoring of heart failure symptoms and daily weights over the telephone assists with intervening efficiently and can prevent exacerbations and hospital readmissions. The future of managing patients with telephone calls is strong. Future research is needed to determine the effectiveness of emerging technologies including formal heart failure monitoring systems, mobile phones, and internet surveillance.

\section{Recommendations}

There are several program recommendations for this facility as a result of this practice change activity. It is evident from the literature tight disease control, frequent monitoring and follow-up, and timely responses to increasing heart failure symptoms are the key elements to a successful heart failure management program. The main recommendations would be to develop a formal heart failure program for the surrounding communities. The program needs further development both in inpatient and outpatient services.

A strong recommendation aimed at the inpatient services is to develop a dedicated inpatient heart failure team. This team would be responsible for the daily management of inpatient heart failure services, heart failure education, optimizing participants, and discharging 
patients to the appropriate level of care. Patients should be stratified to accurate functional classification. All four patients who were readmitted in this program were readmitted within the first few days after discharge. Further exploration is needed in this area to determine if these patients were not optimized before discharge, were not discharged to the appropriate level of care, or were not prepared with the appropriate medications or education at the time of discharge. A formal multidisciplinary heart failure rounding team consisting of heart failure providers, nursing, pharmacists, dietary, and social work could help to ensure the patient is optimized, has the proper education, and is able to care for themselves upon returning home. Strong relationships with outside resources such as home health agencies with dedicated heart failure programs and hospice services would also be helpful. Developing a palliative care program for heart failure patients at this facility would also have a major benefit.

It is recommended the outpatient telephone program also continue for the heart failure product line. A discharge phone call should take place within 24 hours after hospital discharge and continue weekly for a 30 day period. An outpatient clinic should be made available with a clinic visit within the first seven days after discharge. The formal heart failure rehabilitation program should continue with vigorous efforts to enroll appropriate participants. This type of formal product line management could easily be implemented in other practice settings or applied to other chronic illnesses. 


\section{Appendix A}

\section{Heart Failure Evidence-Based Treatment Protocol: Patients with Reduced Left Ventricular Ejection Fraction with current or prior Heart Failure (HF) Symptoms}

\begin{tabular}{|c|c|}
\hline Recommendation & Level of Evidence \\
\hline $\begin{array}{l}\text { Diuretics for current or prior symptoms of } \\
\text { HF }\end{array}$ & Class I Level C \\
\hline Sodium Restriction (2000 mg Sodium Diet) & Class I Level C \\
\hline $\begin{array}{l}\text { Angiotensin-converting Enzyme Inhibitors } \\
\text { (ACE-Inhibitors) or documentation of } \\
\text { contraindication }\end{array}$ & Class I Level A \\
\hline $\begin{array}{c}\text { Beta Blockers (Bisoprolol, Carvedilol, } \\
\text { Metoprolol Succinate or documentation of } \\
\text { contraindication }\end{array}$ & Class I Level A \\
\hline $\begin{array}{l}\text { Angiotensin II Receptor Blockers (ARBS) } \\
\text { for patients who are ACE intolerant }\end{array}$ & Class I Level A \\
\hline $\begin{array}{l}\text { Avoid medications known to adversely } \\
\text { affect the clinical status of patients with } \\
\text { current or prior symptoms of HF } \\
\text { (Nonsteroidal anti-inflammatory drugs, } \\
\text { most antiarrhythmic drugs, most calcium } \\
\text { channel blocking drugs) }\end{array}$ & Class I Level B \\
\hline Exercise Training & Class I Level B \\
\hline $\begin{array}{l}\text { Implantable Cardioverter-Defibrillator } \\
\text { Therapy for LVED less than or equal to } \\
35 \%\end{array}$ & Class I Level A \\
\hline $\begin{array}{l}\text { Cardiac Resynchronization Therapy (BiV } \\
\text { ICD) LVEF less than or equal to } 35 \% \text { with } \\
\text { QRS > or equal to } 0.12 \text { seconds }\end{array}$ & Class I Level A \\
\hline $\begin{array}{c}\text { Aldosterone Antagonist with moderate to } \\
\text { severe symptoms with preserved renal } \\
\text { function and normal potassium } \\
\text { concentration }\end{array}$ & Class I Level B \\
\hline $\begin{array}{l}\text { African-Americans-Combination of } \\
\text { Hydralazine and Nitrates with moderate- } \\
\text { severe symptoms on optimal therapy with } \\
\text { ACE inhibitors, beta blockers and diuretics }\end{array}$ & Class I Level B \\
\hline
\end{tabular}




\section{Appendix B}

\section{Patient Education}

Patient education wasbe completed during each phone call as needed.

\begin{tabular}{|l|l|}
\hline \multicolumn{1}{|c|}{ Activity } & \multicolumn{1}{|c|}{ Recommendations } \\
\hline Signs of worsening Heart Failure & $\begin{array}{l}\text { Weight gain }>5 \text { pounds, shortness of } \\
\text { breath, fatigue, selling in lower legs or } \\
\text { abdomen, persistent cough, change in } \\
\text { symptoms }\end{array}$ \\
\hline Weight Monitoring Instructions & $\begin{array}{l}\text { Weight at the same time on the same scale } \\
\text { with the same amount of clothing on. } \\
\text { Record daily weights }\end{array}$ \\
\hline Medication compliance & $\begin{array}{l}\text { Medications are a very important part of } \\
\text { the treatment plan and should be taken as } \\
\text { prescribed. Is patient taking and tolerating } \\
\text { medications? }\end{array}$ \\
\hline Activity Level & $\begin{array}{l}\text { Cardiac Rehab? Tolerating activities of } \\
\text { daily living? Regular exercise? }\end{array}$ \\
\hline Diet & $\begin{array}{l}\text { Is the patient about to follow Low Sodium } \\
\text { Diet? What did you eat today for } \\
\text { breakfast? Dinner last night? }\end{array}$ \\
\hline General Questions & $\begin{array}{l}\text { Provide time for general questions as } \\
\text { needed }\end{array}$ \\
\hline
\end{tabular}




\section{Appendix C}

\section{Phone Call Protocol}

Participating patients will be called on a weekly basis for a total of 4 weeks. Week one will begin on the next working day after discharge from the in-patient facility. Appropriate times for the phone calls will be negotiated during the time of enrollment. If contact is not made during the scheduled time, contact will be attempted during the remainder of the week and the following week. If the patient is not contacted for two consecutive weeks, then the patient will not be included in the study data. During the fourth phone call, the MLHF-Q and HADS Questionnaires will be completed. If the patient is unable to be contacted on the $4^{\text {th }}$ week, then contact will be attempted for the next two weeks to obtain the questionnaires. If contact is not made within the two week period, patient data will not be included in the study. At any time, if patient is not able to be contacted, it will be verified that the patient has not been admitted into the hospital. If the patient has been admitted, then the four weeks will begin at discharge and the admission will be included in the 30-day readmission rates.

\section{Week One}

$\mathrm{Hi} \mathrm{Mrs} / \mathrm{Mr}$ this is Brooke Leaberry calling from St. Mary's MedicalCenter's Heart Failure Team. I wanted to call and see how you were doing since you have been home. How are you feeling today? Has anything changed since you were in the hospital that you are concerned about? Any changes in your symptoms since you were here? (I will have the patient information in front of me and discuss particular symptoms that were pertinent to each patient) Do you remember the worsening signs of heart failure to be looking for?

Were you able to get your scale home we gave you at the hospital? Did you weigh yourself today? Any change in your weight? What was your weight today? Were you able to record your weight on the documentation form? Emphasize the importance of weighing at the same time each day, on the same scale, with the same amount of clothing on, and document.

Were you able to pick up your medications from the Pharmacy? (I will have a list of each patient's discharge medications and address each heart failure medication specifically) Do you have any questions about how to take these medications? Do you seem to be tolerating these medications so far?

How is your energy level today? Were you able to get your bath and your clothing changed today? Are you getting around the house and to the bathroom? Did you fix your breakfast this morning? Did you think anymore about or have questions about the Cardiac rehab program that we discussed at the hospital?

What did you have for breakfast today? Did you have any questions about the low sodium diet we gave you at the hospital? Do you have food at home or are you going to go to the grocery store soon? 
Have you needed to go to the emergency room, be admitted to the hospital or see your doctor since you were discharged from the hospital?

Do you have any questions about your care? Is there anything you are concerned about? I will be calling you during this time for the next four weeks. If you have questions you can contact me at 304-3994703 or 304-526-6029.

\section{Week Two-Three}

$\mathrm{Hi} \mathrm{Mrs} / \mathrm{Mr}$ this is Brooke Leaberry calling from St. Mary's MedicalCenter's Heart Failure Team. How are you feeling today? Has anything changed since last week that you are concerned about? Any change in your symptoms since last week? (I will have the patient information in front of me and discuss particular symptoms that were pertinent to each patient) Do you remember the worsening signs of heart failure to be looking for?

Did you weigh yourself today? Any change in your weight? What was your weight today? Were you able to record your weight on the documentation form? Emphasize the importance of weighing at the same time each day, on the same scale, with the same amount of clothing on, and document.

Have you been taking your medications? (I will have a list of each patient's discharge medications and address each heart failure medication specifically) Do you have any questions about how to take these medications? Do you seem to be tolerating these medications so far?

How is your energy level today? Were you able to get your bath and your clothing changed today? Are you getting around the house and to the bathroom? Did you fix your breakfast this morning? Did you think anymore about or have questions about the Cardiac rehab program that we discussed at the hospital?

What did you have for breakfast today? Did you have any questions about the low sodium diet we gave you at the hospital? Do you have food at home or are you going to go to the grocery store soon?

Have you needed to go to the emergency room, be admitted to the hospital or see your doctor since the last time I called?

Do you have any questions about your care? Is there anything you are concerned about? I will be calling you during this time for the next four weeks. If you have questions you can contact me at 304-3994703 or 304-526-6029.

\section{Week Four}

$\mathrm{Hi} \mathrm{Mrs} / \mathrm{Mr}$ this is Brooke Leaberry calling from St. Mary's MedicalCenter's Heart Failure Team. How are you feeling today? Any changes in your symptoms since last week? (I will have the patient information in front of me and discuss particular symptoms that were 
pertinent to each patient) Do you remember the worsening signs of heart failure to be looking for?

Did you weigh yourself today? Any change in your weight? What was your weight today? Were you able to record your weight on the documentation form? Emphasize the importance of weighing at the same time each day, on the same scale, with the same amount of clothing on, and document.

Are you taking your medications as prescribed? (I will have a list of each patient's discharge medications and address each heart failure medication specifically) Do you have any questions about how to take these medications? Do you seem to be tolerating these medications so far?

How is your energy level today? Were you able to get your bath and your clothing changed today? Are you getting around the house and to the bathroom? Did you fix your breakfast this morning? Did you think anymore about or have questions about the Cardiac rehab program that we discussed at the hospital?

What did you have for breakfast today? Did you have any questions about the low sodium diet we gave you at the hospital? Do you have food at home or are you going to go to the grocery store soon?

Have you needed to go to the emergency room, be admitted to the hospital or see your doctor since the last time I called?

Do you have any questions about your care? Is there anything you are concerned about?

Administer the MLHF-Q and HADS Questionnaire

This will be the last phone call for the program. When is your follow-up appointment with your regular physician? Please call me anytime, if you find you have questions or concerns. 


\section{Appendix D}

\section{Heart Failure Budget}

\begin{tabular}{|c|c|c|}
\hline PERSONEL & BUDGET & TOTAL \\
\hline Secretary & 2,500 & 2,500 \\
\hline Nurse Practitioner & 23,750 & TOTAL \\
\hline OPERATING & BUDGET & 0 \\
\hline Monitoring Equipment & 0 & 10,000 \\
\hline Employee Benefits & 10,000 & 0 \\
\hline Mainenance/Warrenty & 0 & 1,000 \\
\hline Office Supplies & 1,000 & 100 \\
\hline Postage & 100 & 240 \\
\hline Telephone & 240 & 37,710 \\
\hline Utilities & 120 & 120 \\
\hline & & \\
\hline Total Annual Budget & & \\
\hline
\end{tabular}




\section{Appendix E}

\section{MINNESOTA LIVING WITH HEART FAILURE ${ }^{\circledR}$ QUESTIONNAIRE}

The following questions ask how much your heart failure (heart condition) affected your life during the past month (4 weeks). After each question, circle the $0,1,2,3,4$ or 5 to show how much your life was affected. If a question does not apply to you, circle the 0 after that question.

Did your heart failure prevent you from living as you wanted during the past month ( 4 weeks) by -

\begin{tabular}{ccc} 
Very & Very \\
No & Little & Much \\
\hline
\end{tabular}

1. causing swelling in your ankles or legs?

2. making you sit or lie down to rest during the day?

3. making your walking about or climbing stairs difficult?

4. making your working around the house or yard difficult?

5. making your going places away from home difficult?

6. making your sleeping well at night difficult?

7. making your relating to or doing things with your friends or family difficult?

8. making your working to earn a living difficult?

9. making your recreational pastimes, sports or hobbies difficult?

10. making your sexual activities difficult?

11. making you eat less of the foods you like?

12. making you short of breath?

13. making you tired, fatigued, or low on energy?

14. making you stay in a hospital?

15. costing you money for medical care?

16. giving you side effects from treatments?

17. making you feel you are a burden to your family or friends?

18. making you feel a loss of self-control in your life?

19. making you worry?

20. making it difficult for you to concentrate or remember things?

21. making you feel depressed?

\begin{tabular}{|c|c|c|c|c|}
\hline 0 & 1 & 2 & 3 & 4 \\
\hline 0 & 1 & 2 & 3 & 4 \\
\hline 0 & 1 & 2 & 3 & 4 \\
\hline 0 & 1 & 2 & 3 & 4 \\
\hline 0 & 1 & 2 & 3 & 4 \\
\hline 0 & 1 & 2 & 3 & 4 \\
\hline 0 & 1 & 2 & 3 & 4 \\
\hline 0 & 1 & 2 & 3 & 4 \\
\hline 0 & 1 & 2 & 3 & 4 \\
\hline 0 & 1 & 2 & 3 & 4 \\
\hline 0 & 1 & 2 & 3 & 4 \\
\hline 0 & 1 & 2 & 3 & 4 \\
\hline 0 & 1 & 2 & 3 & 4 \\
\hline 0 & 1 & 2 & 3 & 4 \\
\hline 0 & 1 & 2 & 3 & 4 \\
\hline 0 & 1 & 2 & 3 & 4 \\
\hline 0 & 1 & 2 & 3 & 4 \\
\hline 0 & 1 & 2 & 3 & 4 \\
\hline 0 & 1 & 2 & 3 & 4 \\
\hline 0 & 1 & 2 & 3 & 4 \\
\hline 0 & 1 & 2 & 3 & 4 \\
\hline
\end{tabular}

C1986 Regents of the University of Minnesota, All rights reserved. Do not copy or reproduce without permission. LIVING WITH HEART FAILURE® is a registered trademark of the Regents of the University of Minnesota. $11 / 10 / 04$ 


\section{Hospital Anxiety and Depression Scale (HADS)}

Patients are asked to choose one response from the four given for each interview. They should give an immediate response and be dissuaded from thinking too long about their answers. The questions relating to anxiety are marked "A", and to depression " $D$ ". The score for each answer is given in the right column. Instruct the patient to answer how it currently describes their feelings.

\begin{tabular}{l|l|}
\hline A I feel tense or 'wound up': & \\
\hline Most of the time & 3 \\
\hline A lot of the time & 2 \\
\hline From time to time, occasionally & 1 \\
\hline Not at all & 0 \\
\hline
\end{tabular}

\begin{tabular}{|l|l|l|}
\hline D & $\begin{array}{l}\text { I still enjoy the things I used to } \\
\text { enjoy: }\end{array}$ & \\
\hline Definitely as much & 0 \\
\hline Not quite so much & 1 \\
\hline Only a little & 2 \\
\hline Hardly at all & 3 \\
\hline
\end{tabular}

I get a sort of frightened

A feeling as if something awful is about to happen:

Very definitely and quite badly

Yes, but not too badly

A little, but it doesn't worry me

Not at all

\begin{tabular}{|l|}
\hline \\
\hline 3 \\
\hline 2 \\
\hline 1 \\
\hline
\end{tabular}




\begin{tabular}{|l|l|}
\hline D & $\begin{array}{l}\text { I can laugh and see the funny } \\
\text { side of things: }\end{array}$ \\
\hline As much as I always could & 0 \\
\hline Not quite so much now & 1 \\
\hline Definitely not so much now & 2 \\
\hline Not at all & 3 \\
\hline
\end{tabular}

\begin{tabular}{|c|c|c|}
\hline A & $\begin{array}{l}\text { Worrying thoughts go through } \\
\text { my mind: }\end{array}$ & \\
\hline & A great deal of the time & 3 \\
\hline & A lot of the time & 2 \\
\hline & $\begin{array}{l}\text { From time to time, but not too } \\
\text { often }\end{array}$ & 1 \\
\hline & Only occasionally & 0 \\
\hline
\end{tabular}

\begin{tabular}{|l|l|}
\hline D & I feel cheerful: \\
\hline Not at all & 3 \\
\hline Not often & 2 \\
\hline Sometimes & 1 \\
\hline Most of the time & 0 \\
\hline
\end{tabular}

\begin{tabular}{|l|l|}
\hline $\begin{array}{l}\text { I can sit at ease and feel } \\
\text { relaxed: }\end{array}$ & \\
\hline Definitely & 0 \\
\hline Usually & 1 \\
\hline Not Often & 2 \\
\hline Not at all & 3 \\
\hline
\end{tabular}




\begin{tabular}{|c|c|c|}
\hline $\mathrm{D}$ & I feel as if I am slowed down: & \\
\hline & Nearly all the time & 3 \\
\hline & Very often & 2 \\
\hline & Sometimes & 1 \\
\hline & Not at all & 0 \\
\hline
\end{tabular}

\begin{tabular}{|l|l|}
\hline $\begin{array}{l}\text { I get a sort of frightened } \\
\text { feeling like 'butterflies' in the } \\
\text { stomach: }\end{array}$ & \\
\hline Not at all & 0 \\
\hline Occasionally & 1 \\
\hline Quite Often & 2 \\
\hline Very Often & 3 \\
\hline
\end{tabular}

\begin{tabular}{|c|c|c|}
\hline D & $\begin{array}{l}\text { I have lost interest in my } \\
\text { appearance: }\end{array}$ & \\
\hline & Definitely & 3 \\
\hline & $\begin{array}{l}\text { I don't take as much care as I } \\
\text { should }\end{array}$ & 2 \\
\hline & $\begin{array}{l}\text { I may not take quite as much } \\
\text { care }\end{array}$ & 1 \\
\hline & I take just as much care as ever & 0 \\
\hline
\end{tabular}

\begin{tabular}{|l|l|}
\hline A $\begin{array}{l}\text { I feel restless as I have to be on } \\
\text { the move: }\end{array}$ & \\
\hline Very much indeed & 3 \\
\hline Quite a lot & 2 \\
\hline Not very much & 1 \\
\hline
\end{tabular}




\begin{tabular}{l|l|l|}
\hline D & $\begin{array}{l}\text { I look forward with enjoyment } \\
\text { to things: }\end{array}$ \\
\hline As much as I ever did & 0 \\
\hline & Rather less than I used to & 1 \\
\hline Definitely less than I used to & 2 \\
\hline Hardly at all & 3 \\
\hline
\end{tabular}

\begin{tabular}{|c|c|c|}
\hline $\mathrm{A}$ & I get sudden feelings of panic: & \\
\hline & Very often indeed & 3 \\
\hline & Quite often & 2 \\
\hline & Not very often & 1 \\
\hline & Not at all & 0 \\
\hline
\end{tabular}

\begin{tabular}{|l|l|l|}
\hline D & $\begin{array}{l}\text { I can enjoy a good book or } \\
\text { radio or TV program: }\end{array}$ & \\
\hline Often & 0 \\
\hline Sometimes & 1 \\
\hline Not often & 2 \\
\hline Very seldom & 3 \\
\hline
\end{tabular}

Scoring (add the As = Anxiety. Add the Ds = Depression). The norms below will give you an idea of the level of Anxiety and Depression. 


\begin{tabular}{|l|l|}
\hline $0-7=$ Normal \\
\hline $8-10=$ Borderline abnormal \\
\hline $11-21=$ Abnormal
\end{tabular}

Reference:

Zigmond and Snaith (1983) 
Appendix G

\section{Informed Consent to Participate in a Research Study}

An Evaluation of the Effectiveness of a Nurse-Led Telephone Program for Patients with Heart Failure on 30 Day Readmission Rates, Depression, and Quality of Life.

Mark Studeny, M.D., Principal Investigator

Brooke Leaberry, RN, MSN, Nurse Practitioner, Co-Investigator

\section{Introduction}

You are invited to be in a research study. Research studies are designed to gain scientific knowledge that may help other people in the future. You may or may not receive any benefit from being part of the study. There may also be risks associated with being part of research studies. If there are any risks involved in this study then they will be described in this consent. Your participation is voluntary. Please take your time to make your decision, and ask your research doctor or research staff to explain any words or information that you do not understand.

\section{Why Is This Study Being Done?}

The prevalence of heart failure has continued to increase around the world over the past thirty years. Heart failure (HF) is generally a chronic process that results in frequent unplanned hospitalizations, increased mortality and an overall reduction in quality of life. According to the American Heart Association (2009), over five million Americans are living with this disease and 550,000 new cases will be diagnosed this year. The disease process is described as a cardiac abnormality where the ventricles are unable to fill or pump blood efficiently. . It is most common in the elderly population and is also the most commonly documented Medicare hospital discharge diagnosis. The psychological impact of this illness can be overwhelming. Depression and anxiety are frequent complaints of patients with heart failure. Despite aggressive pharmacologic advances and new heart failure implantable devices, the impact associated with heart failure is both expensive and debilitating. Based upon this data, the research question proposed is: In adults with heart failure, what effect does a nurse led telephone intervention have on 30-day hospital readmissions, quality of life, and depression as compared to routine primary provider outpatient follow-up care?

\section{How Many People Will Take Part In The Study?}

About 15-50participants will take part in this study. A total of 50 subjects are the most that would be able to enter the study. 


\section{What Is Involved In This Research Study?}

Participating patients will be called on a weekly basis for a total of 4 weeks. Week one will begin on the next working day after discharge from the in-patient facility. Appropriate times for the phone calls will be negotiated during the time of enrollment. If contact is not made during the scheduled time, contact will be attempted during the remainder of the week and the following week. If the patient is not contacted for two consecutive weeks, then the patient will not be included in the study data. The phone calls will assess heart failure symptoms, evaluate daily weights, assess medical compliance and trouble shoot barriers to compliance, and answer questions the participant may have. During the fourth phone call, the Minnesota Living with Heart Failure-Questionnaire and Hospital Anxiety and Depression Score Questionnaire will be completed. If the patient is unable to be contacted on the $4^{\text {th }}$ week, then contact will be attempted for the next two weeks to obtain the questionnaires. If contact is not made within the two week period, patient data will not be included in the study. At any time, if patient is not able to be contacted, it will be verified that the patient has not been admitted into the hospital. If the patient has been admitted, then the four weeks will begin at discharge and the admission will be included in the 30-day readmission rates. Usual care will continue including regularly scheduled office visits with primary care provider or cardiologists and medication adjustments over the phone by the primary care provider or cardiologists. Participants with increased heart failure symptoms, unexplained weight gain by five pounds, difficulties with the medical management plan will be scheduled an office visit with their primary care provider or cardiologist. Marshall University Cardiovascular Services will be available to see patients without a primary care provider or cardiologists.

\section{How Long Will You Be In The Study?}

You will be in the study for about 4 weeks.

You can decide to stop participating at any time. If you decide to stop participating in the study we encourage you to talk to the investigators or study staff to discuss what follow up care and testing could be most helpful for you.

The study doctor may stop you from taking part in this study at any time if he/she believes it is in your best interest; if you do not follow the study rules; or if the study is stopped.

\section{What Are The Risks Of The Study?}

Being in this study involves some risk to you. You should discuss the risk of being in this study with the study staff.

You should talk to your study doctor about any side effects that you have while taking part in the study.

Risks of Participation: 
This is an observational study that will require you to respond to four telephone surveys. There are no physical risks associated with this study. There is a potential risk to your privacy. Every effort will be made to maintain your privacy, however, this can not be guaranteed.

There may also be other side effects that we cannot predict. You should tell the research staff about all the medications, vitamins and supplements you take and any medical conditions you have. This may help avoid side effects, interactions and other risks.

\section{Are There Benefits To Taking Part In The Study?}

If you agree to take part in this study, there may or may not be direct benefit to you. We hope the information learned from this study will benefit other people in the future. The benefits of participating in this study may be: increased knowledge of heart failure disease, early recognition and treatment of heart failure related symptoms, increased quality of life, and decreased depressive symptoms related to heart failure.

\section{What Other Choices Are There?}

You do not have to be in this study to receive treatment. You should talk to your doctor about all the choices you have. Instead of being in this study, you have these options: Follow-up office visits with your primary care provider.

\section{What About Confidentiality?}

We will do our best to make sure that your personal information is kept confidential. However, we cannot guarantee absolute confidentiality. Federal law states that we must keep your study records private. Nevertheless, certain people other than your researchers may also need to see your study records. By law, anyone who looks at your records must keep them completely confidential.

Those who may need to see your records are:

- Certain university and government people who need to know more about the study. For example, individuals who provide oversight on this study may need to look at your records. These include the Marshall University Institutional Review Board (IRB) and the Office of Research Integrity (ORI). Other individuals who may look at your records include: thefederal Office of Human Research Protection, Representative of St. Mary's MedicalCenter and Study staff. This is done to make sure that we are doing the study in the right way. They also need to make sure that we are protecting your rights and your safety. 
If we publish the information we learn from this study, you will not be identified by name or in any other way.

\section{What Are The Costs Of Taking Part In This Study?}

There are no costs to you for taking part in this study. All the study costs, including any study medications and procedures related directly to the study, will be paid for by the study. Costs for your regular medical care including all regularly scheduled or additionally scheduled visits, which are not related to this study, will be your own responsibility.

\section{Will You Be Paid For Participating?}

You will receive no payment or other compensation for taking part in this study.

\section{Who Is Sponsoring This Study?}

There is no Sponsor for this Study.

\section{What Are Your Rights As A Research Study Participant?}

Taking part in this study is voluntary. You may choose not to take part or you may leave the study at any time. Refusing to participate or leaving the study will not result in any penalty or loss of benefits to which you are entitled. If you decide to stop participating in the study we encourage you to talk to the investigators or study staff first to learn about any potential health or safety consequences.

\section{Whom Do You Call If You Have Questions Or Problems?}

For questions about the study or in the event of a research-related injury, contact the study coinvestigator, Brooke Leaberry at 304-526-6029 or 304-208-5330. You should also call the investigator if you have a concern or complaint about the research.

For questions about your rights as a research participant, contact the Marshall University Institutional Official, Dr. Henry Dirscoll, IRB \#1 Chair at 304-696-7320. You may also call this number if:

- You have concerns or complaints about the research.

$\circ$ The research staff cannot be reached.

o You want to talk to someone other than the research staff. 
You will be given a signed and dated copy of this consent form.

\section{SIGNATURES}

You agree to take part in this study and confirm that you are 18 years of age or older. You have had a chance to ask questions about being in this study and have had those questions answered. By signing this consent form you are not giving up any legal rights to which you are entitled.

\section{Subject Name (Printed)}

Subject Signature

Person Obtaining Consent

Principal Investigator

Witness (If not applicable, omit this line)

\section{Date}

Date

Date 


\section{References}

American Heart Association. (2009). Heart failure. Retrieved April 1, 2009, from WWW.americanheart.org

Anderson, K. M. (2008). Clinical uses of brain natriuretic peptide in diagnosis and managing heart failure. Journal of the AmericanAcademy of Nurse Practitioners, 20, 305-310.

Antonicelli, R., Testarmata, P., Spazzafumo, L., Gagliardi, C., Grzegorz, B., \&Valentini, M. et al. (2008). Impact of telemonitoring at home on the management of elderly patients with congestive heart failure. Journal of Telemedicine and Telecare, 14, 300-305.

Bakan, G., \&Akyol, A. (2007). Theory-guided interventions for adaptation to heart failure. Journal of Advanced Nursing, 61, 596-608.

Bocchi, E., Cruz, F., Guimaraes, G., Moreira, L., Issa, V., Ferreira, S., Chizzola, P., \& Souza, G. (2008). Long-term prospective, randomized, controlled study using repetitive education at six-month intervals and monitoring for adherence in heart failure outpatients: The REMADHE trial. Circulation Heart Failure, 1, 115-124.

Center for Disease Control. (2010). Data and Statistics. Retrieved from www.cdc.gov/datastatistics

Clark, R., Inglis, S., McAlister, F., Cleland, J., \& Stewart, S. (2007). Telemonitoring or structured telephone support program with chronic heart failure: systematic review and meta-analysis. British Medicine Journal, 5, 942-949.

Cole, S., Farber, N., Weiner, J., Sulfaro, M., Katzelnick, D., \&Blader, J. (2006). Double-disease management or one care manager for two chronic conditions: pilot feasibility study of nurse telephonic disease management for depression and congestive heart failure.

Disease Management, 9, 266-276. 
Dansky, K., Visy, J., \& Bowles, K. (2008). Impact of telehealth on clinical outcomes in patients with heart failure. Clinical Nursing Research, 17, 182-199.

Department of Health and Human Resources (2002). The burden of cardiovascular disease in West Virginia. Retrieved October 28, 2008, from www.wvdhhr.org

Dunderdale, K., Thompson, D., Miles, J., Beer, S., \& Furze, G. (2004). Quality-of-life measurement in chronic heart failure: do we take account of the patient perspective? The European Journal of Heart Failure, 7, 572-582.

Eliaszadeh, P., Yarmohammadi, H., Nawaz, H., Boukhalil, J., \& Katz, D. (2001). Congestive heart failure case management: A fiscal analysis. Disease Management, 4, 25-32.

Ferrante, D., Varini, S., Macchia, A., Soifer, S., Badra, R., Nul, D., ... Doval, H. (2010). Longterm relults after a telephone intervention in chronic heart failure: DIAL follow-up. Journal of the AmericanCollege of Cardiology, 56, 372-378.

Gesica Investigators, (2005). Randomized trial of telephone intervention in chronic heart failure: DIAL trial. British Medicine Journal, 331, 1-5.

Giordano, A., Scalvini, S., Zanelli, E., Corra, U., Longobardi, G., \& Ricci, V. et al. (2009). Multicenter randomized trial on home-based telemanagement to prevent hospital readmission of patients with chronic heart failure. International Journal of Cardiology, $131,192-199$.

Hunt, S., Abraham, W., Chin, M., Feldman, A., Francis, G., \&Ganiats, T. et al. (2009). 2009 Focused update incorporated into the ACC/AHA 2005 guidelines for the diagnosis and management of heart failure in adults: A report of the AmericanCollege of Cardiology Foundation/American Heart Association Task Force on Practice Guidelines developed in 
collaboration with the International society for Heart and Lung Transplantation. Journal of the AmericanCollege of Cardiology, 53, 1-90.

Inglis, S., Clark, R., McAlister, F., Ball, J., Lewinter, C., Cullington, D., ... Cleland, J. (2010). Structured telephone support or telemonitoringprogrammes for patients with chronic heart failure (review). The Cochrane Library, 1-138. doi: www.thecochranelibrary.com

Klersy, C., Silvestri, A., Gabutti, G., Raisaro, A., Curti, M., Regoli, F., \&Auriccio, A. (2011). Econonmic impact of remote patient monitoring: an integrated economic model derived from a meta-analysis of randomized controlled trials in heart failure. The European Journal of Echocardiography, 13, 450-459.

Martensson, J., Stromberg, A., Dahlstrom, U., Karlsson, J., \&Fridlund, B. (2005). Patients with heart failure in primary health care: effects of a nurse-led intervention on health-related quality of life and depression. The European Journal of Heart Failure, 7, 393-403. doi: Retrieved from

Meyers, K. (n.d.). The Roy Adaptation Model: History. Retrieved October 7, 2009, from www2.bc.edu/-royca/htm/ram/htm

Middel, B., \&Bouma, J. (2001). Psychometric properties of the Minnesota Living with Heart Failure Questionnaire. Clinical Rehabilitation, 15, 489-500.

Morcillo, C., Aguado, O., Delas, J., \&Rosell, F. (2007). Utility of the Minnesota Living with Heart Failure Questionnaire for assessing Quality of life in heart failure patients. Rev EspCardiol, 60, 1093-1096.

Newman, M. (2002). A specialist nurse intervention reduced hospital readmissions in patients with chronic heart failure. Evidence Based Nursing, 5, 55. 
Olsson, I., Mykleton, A., \& Dahl, A. (2005). The Hospital Anxiety and Depression Rating Scale: a cross-section study of psychometrics and case finding abilities in general practice. $B M C$ Psychiatry, 5, 1-7. doi: Retrieved from

Parajon, T., Lupon, J., Gonzalez, B., Urrutia, A., Altimir, S., Coll, R., Prats, M., \& Valle, V. (2006, August 24). Use of the "Minnesota Living with Heart Failure" quality of life questionnaire in Spain. Revisat Espanola de Cardiologia, 57, 155-160.

Rector, T., \& Cohn, J. (1992). Assessment of patient outcome with the Minnesota Living with Heart Failure questionnaire: reliability and validity during a randomized, double-blind, placebo-controlled trial of pimobendan. American Heart Journal, 124, 1017-1025.

Rector, T., \& Cohn, J. (2005). Minnesota Living with Heart Failure Questionnaire. Retrieved February 03, 2010, from www.mlhfq.org

Retrieved 2/14/2010, from www.mlhf.org/_dnld/mlhfq_overview.pdf

Rogers, C., \& Keller, C. (2009). Roy's Adaptation Model to promote physical activity among sedentary older adults. Geriatric Nursing, 30, 21-26.

Roy, C. (1997). Future of the Roy Model: Challenge to redefine adaptation. Nursing Science Quarterly, 10, 42-48.

Scherer, M. (2007). Psychological distress in primary care patients with heart failure: a longitudinal study. British Journal of general Practice, 57 801-807.

Scottish Intercollegiate Guidelines Network (2007). Management of chronic heart failure: A national clinical guideline. Retrieved September 14, 2009, from www.sign.ac.uk

St. Mary's MedicalCenter (2008). Mission/Values. Retrieved March 31, 2009, from www.stmarys.org 
St. Mary's MedicalCenter. (2009). Heart Failure Admissions and Expense Report. St. Mary’s Medical Center Hospital Information

The Agree Research Trust (2006). Retrieved November 28, 2008, from www.agreetrust.org

Thompson, D. (2008). Telehome monitoring reduced readmissions and improved quality of life in heart failure or angina. Evidenced Based Nursing, 11, 86.

Zigmond, A., \&Snaith, R. (1983). The hospital anxiety and depression scale. ActaPsychiatricaScandinavica, 67, 361-370. 